Article

\title{
Thermal Analysis of Plastics Used in the Food Industry
}

\author{
Małgorzata Majder-Łopatka ${ }^{1, *(\mathbb{D})}$, Tomasz Węsierski ${ }^{1}$, Artur Ankowski ${ }^{1}{ }^{(}$, Kamil Ratajczak $^{2}$, Dominik Duralski ${ }^{3}$, \\ Aleksandra Piechota-Polanczyk ${ }^{4}(\mathbb{D})$ and Andrzej Polanczyk ${ }^{2}$ (i)
}

1 Institute of Safety Engineering, The Main School of Fire Service, 52/54 Slowackiego Street, 01-629 Warsaw, Poland; twesierski@sgsp.edu.pl (T.W.); aankowski@sgsp.edu.pl (A.A.)

2 Faculty of Safety Engineering and Civil Protection, The Main School of Fire Service, 52/54 Slowackiego Street, 01-629 Warsaw, Poland; kamil.ratajczak0898@gmail.com (K.R.); apolanczyk@sgsp.edu.pl (A.P.)

3 Institute of Internal Security, The Main School of Fire Service, 52/54 Slowackiego Street, 01-629 Warsaw, Poland; dduralski@sgsp.edu.pl

4 Jagiellonian University, Faculty of Biochemistry, Biophysics and Biotechnology, Department of Medical Biotechnology, Gronostajowa 7 Street, 30-387 Krakow, Poland; aleksandra.piechota-polanczyk@uj.edu.pl

* Correspondence: mmajder@sgsp.edu.pl

Citation: Majder-Łopatka, M.; Węsierski, T.; Ankowski, A.; Ratajczak, K.; Duralski, D.;

Piechota-Polanczyk, A.; Polanczyk, A. Thermal Analysis of Plastics Used in the Food Industry. Materials 2022, 15, 248. https://doi.org/10.3390/ ma15010248

Academic Editor: Sergio Torres-Giner

Received: 9 November 2021

Accepted: 28 December 2021

Published: 29 December 2021

Publisher's Note: MDPI stays neutral with regard to jurisdictional claims in published maps and institutional affiliations.

Copyright: (C) 2021 by the authors. Licensee MDPI, Basel, Switzerland. This article is an open access article distributed under the terms and conditions of the Creative Commons Attribution (CC BY) license (https:// creativecommons.org/licenses/by/ $4.0 /)$.

\begin{abstract}
Fires in landfills, where used plastic packaging waste is discarded, have shown how great a fire hazard these types of materials pose. In this study, the course of thermo-oxidation of samples made of polypropylene (PP), polystyrene (PS), and polyethylene terephthalate (PET) based plastics was determined. Based on an analysis of the dissociation energy of bonds between atoms in a polymer molecule, the mechanisms responsible for the character and course of degradation were observed. It was found that the degradation rate of PP and PS could be a result of the stability of $\mathrm{C}-\mathrm{H}$ bonds on the tertiary carbon atom. In the case of PS, due to facilitated intramolecular hydrogen transfer, stabilization of hydroperoxide, and formation of a stable tertiary alcohol molecule, the onset of degradation is shifted towards higher temperatures than in the case of PP. Notably, the PP fragmentation occurs to a greater extent due to the easier course of $\beta$-scission. In addition, it was found that during a fire, the least amount of heat would be generated by thermo-oxidation of PS-based plastics. This is a result of the formation of a styrene molecule during decomposition that, due to the high stability of bonds in the aromatic ring, escapes from the combustion zone without oxidation. It has been proven that the greatest thermal effect accompanies PET decomposition, during which a phenyl radical is produced, where the $\mathrm{C}-\mathrm{H}$ bonds break more easily in comparison with the bonds of an intact ring.
\end{abstract}

Keywords: differential scanning calorimetry; thermogravimetric; thermal decomposition; polystyrene (PS); polyethylene terephthalate (PET); polypropylene (PP); bond dissociation energy

\section{Introduction}

Due to plastic's excellent performance and extensive practicability, global plastic production has reached above 300 million tons [1]. Plastics include diversified groups of materials [2], which makes it impossible to precisely divide plastics according to one criterion [3]. Therefore, different factors are taken into account, i.e., origin, structure, physical properties, and application [4]. Furthermore, the processing and performance properties of plastics, i.e., rheological, mechanical, thermal, structural, morphologic, and optical properties, were highly improved in recent years. This improvement was achieved using various plastic additives such as stabilizers, colorants, plasticizers, fillers and reinforcing fibers, ultraviolet absorbers, antioxidants, and processing aids, including lubricants and flow promoters [5]. Depending on the chemical structure of the main chain, polymers are divided into two groups. The first group consists of polymers with a carbon backbone, e.g., polyethylene, polypropylene, and hydrocarbon polymers with heteroatoms inside groups such as poly (methyl methacrylate). The second group consists of polymers with a 
heteroatom in the backbone, e.g., oxygen, nitrogen, sulfur, and silicon [6]. Thermosets and thermoplastic materials are highlighted, considering the behavior of the material during heating [7]. Thermoplastic changes into a plastic state when heated and hardens once it has cooled down. However, thermosetting plastics solidify irreversibly when kept at elevated temperatures. Thermoplastic polymers have melting points, whereas thermosetting plastics are relatively rigid solids with a network structure without a melting point. [8]. The thermal decomposition process divides into three basic stages including heating by an external energy source, proper thermal decomposition, and ignition or smoldering of the material, depending on the type of material and the composition of the atmosphere around the sample [9]. Moreover, knowledge about the thermal degradation of polymers, i.e., polystyrene and polyethylene terephthalate, involving the emission of toxic substances, is very important for many commercial applications of these polymers $[10,11]$.

Plastics are used in numerous branches of industry [12]. Packaging accounts for approximately $40 \%$ of all plastics produced since the 1950 s, of which $41 \%$ is used specifically for food or beverages [13]. Food packaging is usually made of plastic due to its lightness, resistance to physical and chemical factors, and low production costs. Most often, it is used in the production of packaging made of plastics based on polyethylene, polypropylene, polyethylene terephthalate, and polystyrene [14,15]. The degradation processes depend on the length of the polymer chain, the additives or the subsequently generated radicals, the temperature, and the environmental composition [16]. However, the reactions of thermooxidative degradation are additionally complicated by the participation of oxygen. It has been suggested that the process starts with the formation of hydroperoxide [17]. In most polymers, the rate of this step in the chain reaction determines the overall rate of oxidation [18].

Burning plastic waste in landfill sites increases the intensity of the fire and is the main source of air pollution $[19,20]$. Most of the time, municipal solid waste containing about $12 \%$ plastic is burnt, releasing toxic gases like polycyclic aromatic hydrocarbons, dioxins, furans, and polychlorinated biphenyls into the atmosphere [21,22]. To identify hazardous substances, rescue units around the world use different measuring techniques, including gas chromatography, infrared spectroscopy, ion mobility spectrometry, and electrochemical methods [21,23,24]. Comprehensive knowledge about thermal analysis plays a crucial role in fire risk assessment and determining the processing and recycling conditions of polymers [23]. Thermal analysis has become the primary approach to studying the combustion characteristics of different materials $[25,26]$. Thermal and thermo-oxidative degradation are the processes that accompany the production, processing, and operation of polymeric materials $[27,28]$. To propose kinetic models for the thermo-oxidative degradation of plastics, a large body of research has been carried out using various experimental techniques and theoretical approaches [29-32]. Both calorimetric and optical methods are used [33,34]. Thermogravimetric analysis (TGA) and differential scanning calorimetry (DSC) are two of the conventional methods to investigate the thermal stability of polymers and composites [35-37]. Based on these methods, extensive experiments have been conducted on the natural properties of different materials [38,39]. Therefore, the objective of this study was to determine the thermal decomposition mechanism of plastic packaging waste, most commonly stored in landfill sites, that has been set on fire. In this study, a series of TG-DSC experiments for plastics made of polypropylene, polystyrene, and polyethylene terephthalate were conducted under specific temperature conditions to determine the course of thermal decomposition.

\section{Materials and Methods}

In the research, the following five types of plastic packaging materials used in the food industry were applied:

- $\quad$ three sample sets made of polypropylene (PP):

- PP-1-cookie wrapper;

- PP-2-cheese tray; 
- PP-3-bread wrapper;

- $\quad$ one sample set made of plastic made of polystyrene (PS):

- PS-1—cheese cup;

- $\quad$ one sample set made of polyethylene terephthalate (PET):

- $\quad$ PET-1 - a bottle of still water.

Additionally, pure polypropylene (PP-0) was tested. Moreover, according to the manufacturer's declaration, the PP granulate is used for the production of plastics used in the food industry.

Each time, the weight of the analyzed sample was equal to $10 \mathrm{mg}$. The samples were analyzed in open alumina crucibles on the TG-DSC sample carrier. The polypropylenebased materials used in the research differed in terms of density (PP-1 $0.93 \mathrm{~g} / \mathrm{cm}^{3}, \mathrm{PP}-2$ $0.92 \mathrm{~g} / \mathrm{cm}^{3}$, and PP-3 $0.91 \mathrm{~g} / \mathrm{cm}^{3}$ ) and flexibility. The most flexible was PP-3, and the least flexible was PP-2. Moreover, the density of PS-1 was equal to $1.05 \mathrm{~g} / \mathrm{cm}^{3}$, while PET-1 was equal to $1.30 \mathrm{~g} / \mathrm{cm}^{3}$.

The tested samples were cut out of plastic packages so that they did not contain any imprints. Next, they were placed in the crucible to ensure that the entire bottom surface of the pan was covered.

The TG-DSC STA 499 F5 Jupiter from Netzsch (Selb, Germany) was applied for thermal decomposition analysis. A corundum furnace allowed samples to be heated up to $1100{ }^{\circ} \mathrm{C}$ with a heating speed in a range from $0.001^{\circ} \mathrm{C} / \mathrm{min}$ to $50{ }^{\circ} \mathrm{C} / \mathrm{min}$. The constant atmospheric parameters for the tests were maintained by supplying synthetic air. Finally, the received results were analyzed using Proteus ${ }^{\circledR}$.(Selb, Germany).

The dynamic method with constant temperature increases in the range of $35-600{ }^{\circ} \mathrm{C}$ was applied for analysis. The temperature increase rate was equal to $10{ }^{\circ} \mathrm{C} / \mathrm{min}$. The samples were analyzed in an atmosphere of synthetic air composed of $20 \%$ volumetric oxygen at a gas flow equal to $80 \mathrm{~mL} / \mathrm{min}$. Moreover, 5.0 purity gases were used in the tests.

The thermal decomposition of the selected plastics was presented as TG and DSC curves. Based on their course, the following parameters were determined using the Proteus ${ }^{\circledR}$ Termal Analysis 8.0.1 software (Netzsch, Selb, Germany):

- the initial temperature of the decomposition process of the sample (beginning of the exothermic reaction);

- the temperature of half mass loss;

- the end temperature of the first step of the decomposition process;

- $\quad$ the mass loss rate for the selected temperatures;

- the energy of endothermic reactions;

- the energy of exothermic reactions.

\section{Results}

Based on the experimental analysis, it was observed that packages made of plastic used for food packaging do not pose a risk in everyday use because their decomposition temperature significantly exceeds the temperature of their use. It has been shown how thermal decomposition proceeds in the presence of oxygen of plastics based on various polymers at a heating rate of $10{ }^{\circ} \mathrm{C} / \mathrm{min}$. Furthermore, it was observed that substances added to the polymers might slow down or accelerate the process of plastic thermal decomposition. It has also been shown that the structure of the material has an impact on the amount of energy that needs to be provided to make specific changes in the material.

\subsection{TG DSC Analysis of Decomposition Process of Plastics Made of Polypropylene}

The decomposition of polypropylene plastics was characterized by a two-step process (Figures 1-3). For the polypropylene samples, the mass loss for the first step was not a constant value. Weight loss was noted in the first stage from 90.7\% (PP-1) to 95.96\% (PP-3). PP-0 indicated similar mass loss at the first stage of decomposition to PP-3 (a 
96.4\% similarity). Furthermore, the highest maximum rate of weight loss for plastics made of polypropylene was recorded for PP-3 $\left(16.4 \% / \mathrm{min}\right.$ at $\left.353.3{ }^{\circ} \mathrm{C}\right)$ and the lowest for PP-1 $\left(10.26 \% / \mathrm{min}\right.$ at $\left.319.7^{\circ} \mathrm{C}\right)$. While for PP-0, it was higher and reached $24.01 \% / \mathrm{min}$ at $291.1^{\circ} \mathrm{C}$.

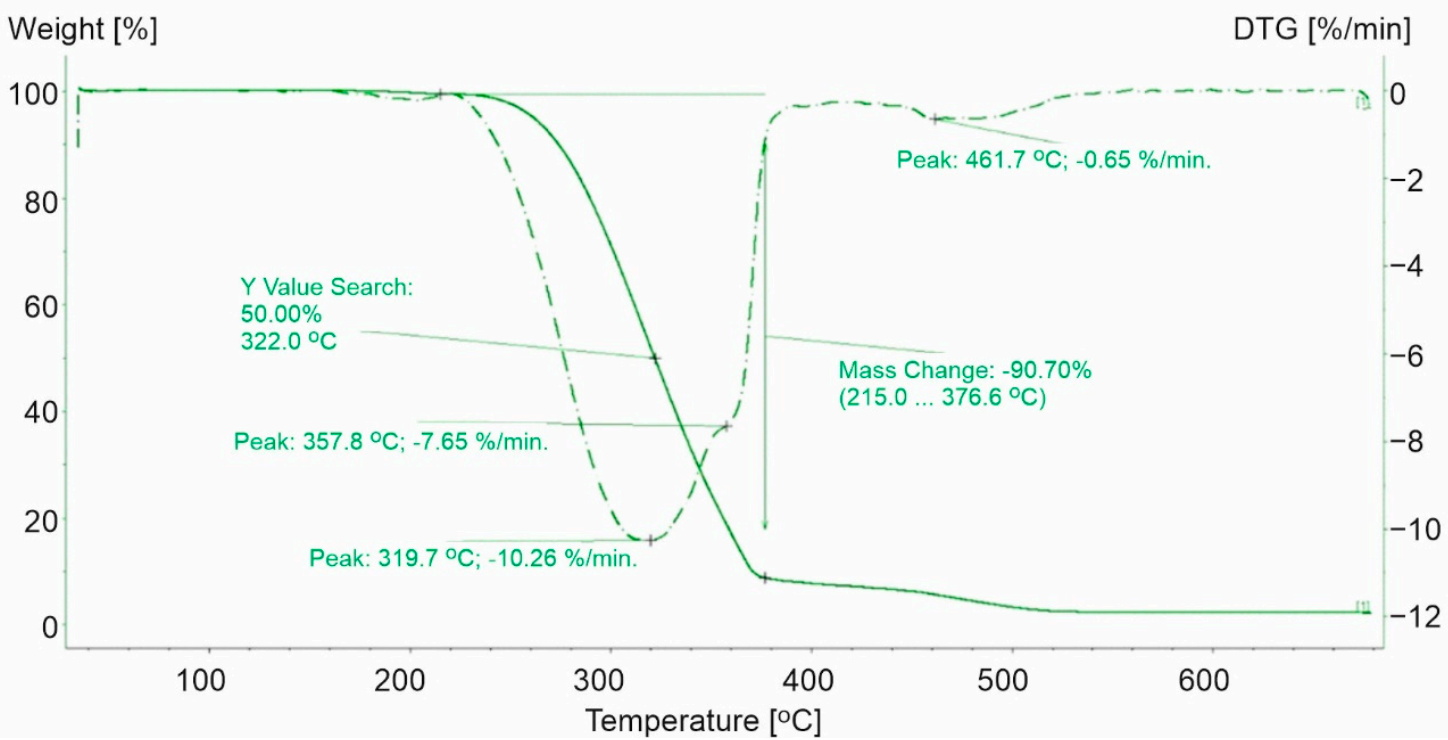

Figure 1. TG and DTG curves for PP-1. The green line presents TG curve, while the green dot line presents DTG curve.

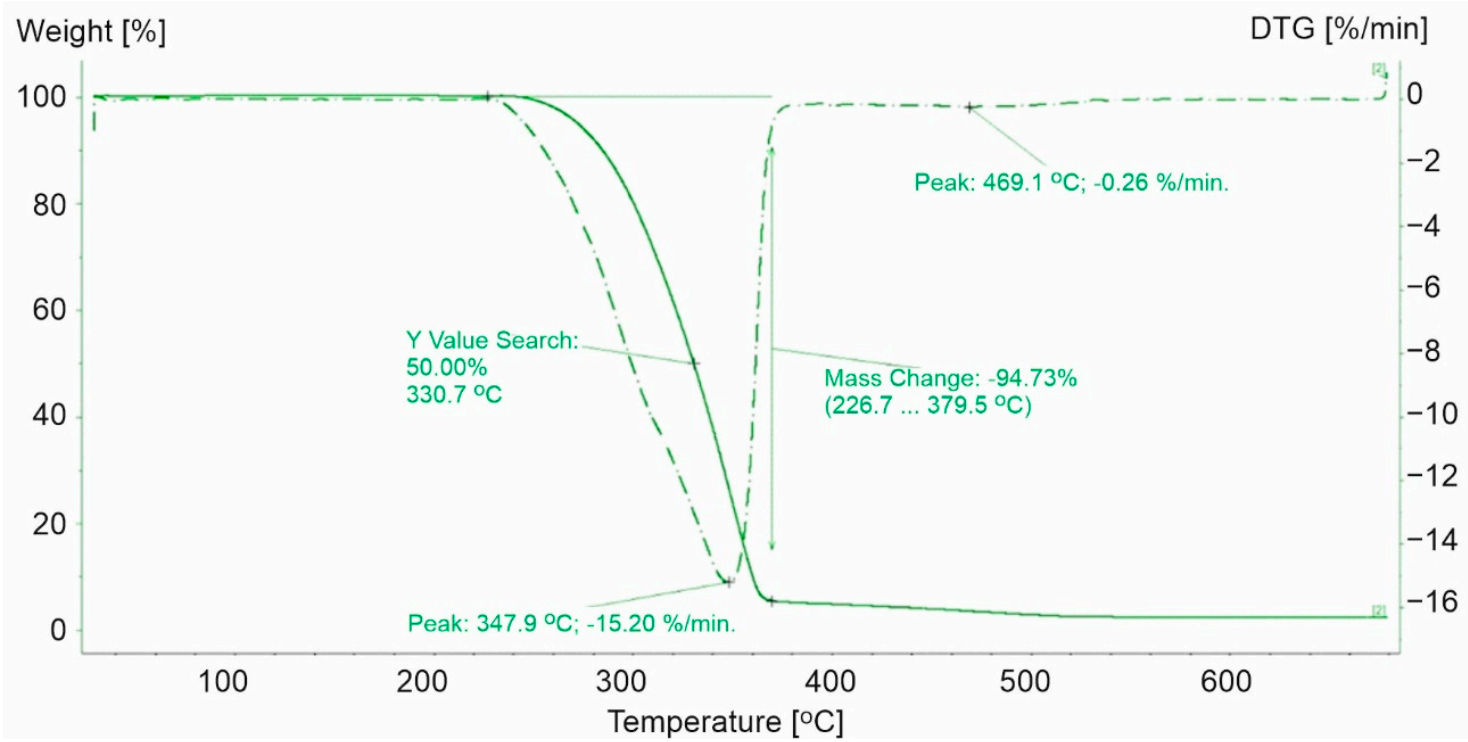

Figure 2. TG and DTG curves for PP-2. The green line presents TG curve, while the green dot line presents DTG curve.

The second step of the decomposition process was characterized by a lower dynamic. The highest decomposition rate was observed for PP-1 $\left(0.65 \% / \mathrm{min}\right.$ at $\left.461.7^{\circ} \mathrm{C}\right)$ (Figure 1$)$, while $0.26 \% / \mathrm{min}$ (Figure 2 ) and $0.32 \% / \mathrm{min}$ (Figure 3 ) were observed for PP-2 and PP-3, respectively. The identified differences in weight loss and decomposition rates confirmed the influence of additional substances on the plastic's decomposition process. The course of the TG and DTG curves for the PP-1 sample compared to the PP-0 sample (Figure 4) indicated a significant share of additives in the mass of the analyzed samples. It has been found that polypropylene-based plastics have wider temperature ranges for thermal decomposition than PP-0 homopolymers. The first stage of decomposition takes place in 
the temperature range of $\mathrm{PP}\left(242-346^{\circ} \mathrm{C}\right)$. The results obtained were consistent with those obtained by Saikrasun and Saengsuwa [30].

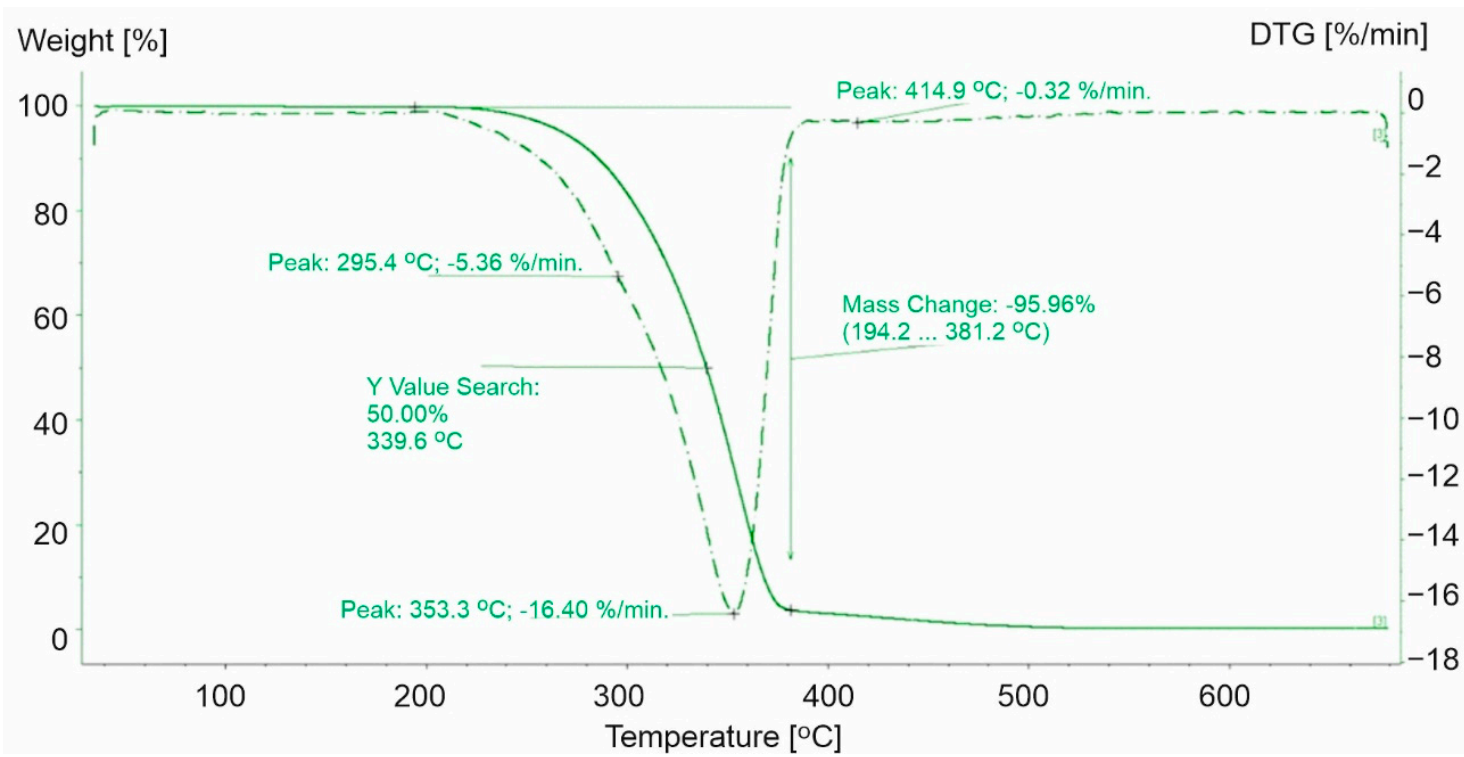

Figure 3. TG and DTG curves for PP-3. The green line presents TG curve, while the green dot line presents DTG curve.

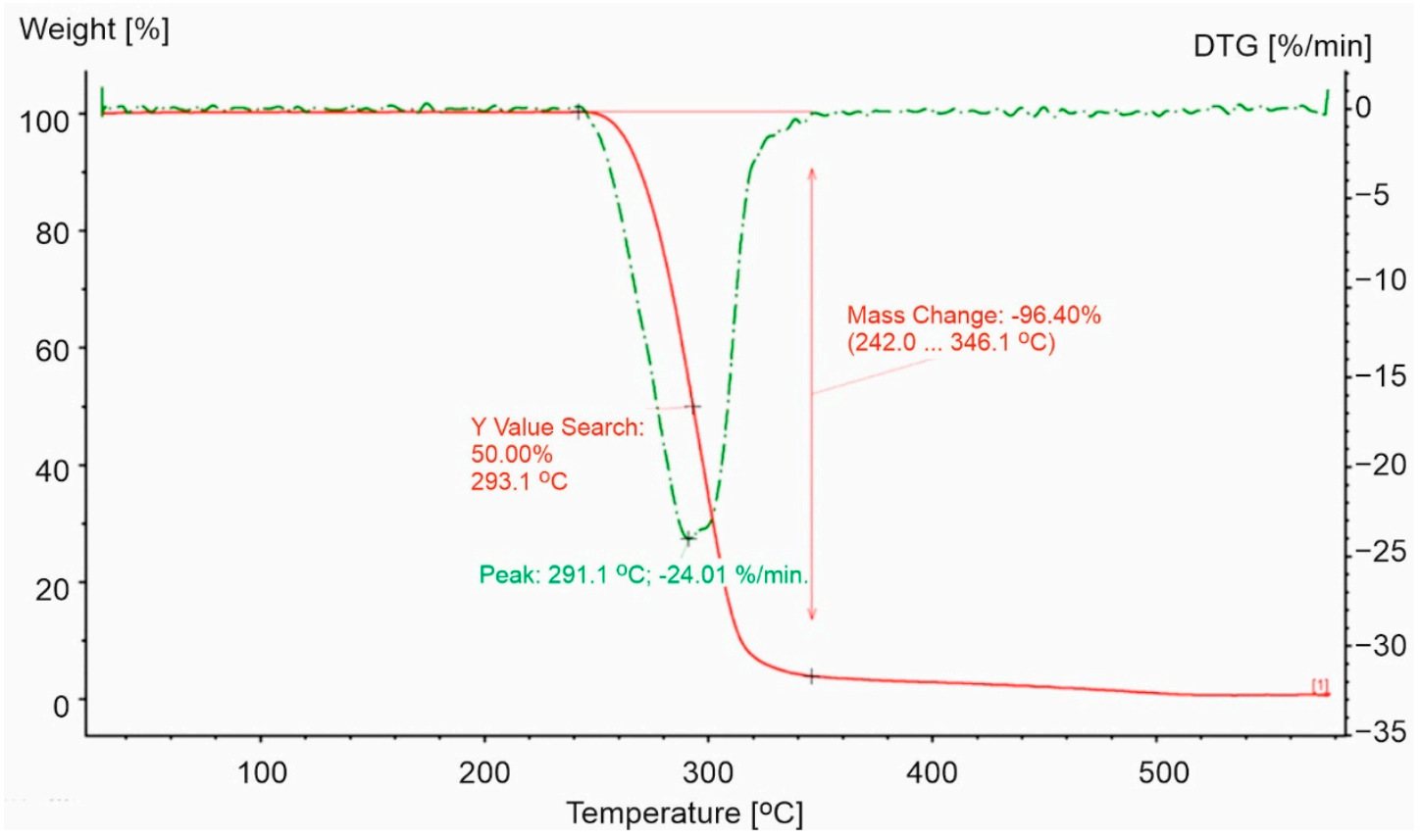

Figure 4. TG and DTG curves for PP-0 in an oxidizing atmosphere $\left(20 \% \mathrm{O}_{2}\right)$. The red line presents TG curve, while the green dot line presents DTG curve.

The lowest decomposition temperature was observed for the PP-3 sample $\left(194.2{ }^{\circ} \mathrm{C}\right)$, and the highest for the PP-2 sample $\left(226.7^{\circ} \mathrm{C}\right)$ (Table 1$)$, while the decomposition temperature for PP-0 was higher at approximately $50{ }^{\circ} \mathrm{C}$ and $20^{\circ} \mathrm{C}$, respectively. Such decomposition temperatures were a result of the copolymeric structure of the material. For instance, the PP-3 sample was characterized by greater plasticity compared to the other samples, which was related to the shift of the initial temperature of the thermal decomposition towards lower values. These observations confirmed the results of the research 
conducted by Chun et al., who found that the structure of the material is an important factor in determining the course of thermal destruction [3].

Table 1. The most important parameters for the thermal decomposition process for PP-0, PP-1, PP-2, and PP-3 samples.

\begin{tabular}{ccccc}
\hline Parameters of Thermal Decomposition & PP-0 & PP-1 & PP-2 & PP-3 \\
\hline Initial decomposition temperature $\left[{ }^{\circ} \mathrm{C}\right]$ & 242.0 & 215.0 & 226.7 & 194.2 \\
End temperature of 1st step of decomposition $\left[{ }^{\circ} \mathrm{C}\right]$ & 346.1 & 376.6 & 369.5 & 381.2 \\
Loss of weight for 1st step of decomposition [\%] & 96.4 & 90.7 & 94.7 & 95.9 \\
Temperature of loss of 50\% of weigh [ $\left.{ }^{\circ} \mathrm{C}\right]$ & 293.1 & 322.0 & 330.7 & 339.6 \\
Maximum rate of weight loss [\%/min] & 24.01 & 10.26 & 15.2 & 16.4 \\
Temperature of maximum rate of weight loss [ $\left.{ }^{\circ} \mathrm{C}\right]$ & 293.1 & 319.7 & 347.9 & 353.3 \\
Maximum rate of weight loss for 2 nd stage [\% $/ \mathrm{min}]$ & & 0.65 & 0.26 & 0.32 \\
Temperature of maximum rate of weight loss for 2 nd stage $\left[{ }^{\circ} \mathrm{C}\right]$ & & 461.7 & 469.1 & 414.9 \\
\hline
\end{tabular}

Moreover, the first step of the thermal decomposition of the tested plastics ended at higher temperatures compared to PP-0 (Table 1). It was noticed that additives increased the limits of thermal decomposition and decreased the dynamics of the process.

Moreover, it was observed that endothermic changes occurring at about $165{ }^{\circ} \mathrm{C}$ were internal changes not related to the sample mass change and emission of products into the atmosphere. The recorded peak related to the melting process had a maximum temperature over $4{ }^{\circ} \mathrm{C}$ lower than that indicated in the study by Wong and Lam [36]. Similarly, an almost constant melting temperature of about $165^{\circ} \mathrm{C}$ for PP was found by Spicker et al. (2019) [40]. Additionally, Brachet et al. (2007) and Navarro et al. (2012) observed the melting point for $\mathrm{PP}$ at $160{ }^{\circ} \mathrm{C}$ or in a range from $164.2^{\circ} \mathrm{C}$ to $166.1^{\circ} \mathrm{C}$, respectively $[41,42]$. Moreover, Paik and Kar have studied the effect of particle size on the kinetics of thermal degradation for PP. They found that with a change in the particle size of PP, the thermal degradation and diffusion mechanism of degradation products are different even at a constant heating rate [43].

Polypropylene film is more ductile than the other products and, therefore, requires less energy for the phase transition. The energy of the PP-3 sample transformation $(27.56 \mathrm{~J} / \mathrm{g})$ was much lower compared to the other analyzed samples (PP-1 $83.65 \mathrm{~J} / \mathrm{g}$ and PP-2 $114.5 \mathrm{~J} / \mathrm{g}$ ) (Figures 5 and 6). After the endothermic peak related to the melting of the sample at a temperature above $200{ }^{\circ} \mathrm{C}$, exothermic peaks associated with the oxidation of the first- and second-order radicals and propene formed during thermal decomposition were recorded [18]. The first exothermic transformation of the PP-2 and PP-3 samples released similar energy (3982 J/g and $3951 \mathrm{~J} / \mathrm{g}$, respectively), while for PP-1, it was equal to $4712 \mathrm{~J} / \mathrm{g}$. The second exothermic reactions correspond to another loss of mass. In the case of the PP-1 sample, during the second stage of decomposition, we recorded the highest loss of weight from all analyzed PPs. The transformation released energy at a level equal to $445.2 \mathrm{~J} / \mathrm{g}$. Lower values equal to $375.9 \mathrm{~J} / \mathrm{g}$ and $332.7 \mathrm{~J} / \mathrm{g}$, respectively (Figures 6 and 7) were noticed for PP-2 and PP-3. The additives used during the production of the PP-1 material increased the energy released during the entire decomposition process compared to the PP-2 and PP-3 samples.

During the first stage of decomposition, two peaks were recorded. The higher of these peaks in PP-2 and PP-3 corresponded to the temperature of the maximum rate of mass loss. For PP-2, peak number three appeared at $350.9^{\circ} \mathrm{C}$, and the fastest mass loss occurred at $347.9^{\circ} \mathrm{C}$. While for PP-3, these values were equal to $355.3^{\circ} \mathrm{C}$ and $353.3^{\circ} \mathrm{C}$. In the case of the PP-1 sample, no such relationship was observed. The maximum speed of mass loss was recorded at $319.7^{\circ} \mathrm{C}$, an exothermic peak at $288.7^{\circ} \mathrm{C}$. Peak number four corresponded to the maximum rates of mass loss during the second stage of decomposition. The analysis of the results of the PP-2 and PP-3 samples allowed the correlation of the reaction energy of exothermic polypropylene materials with the rate of weight loss of the samples. However, the course of the DSC curve for the PP-1 samples did not allow for unambiguous confirmation of this relationship (Table 2). 


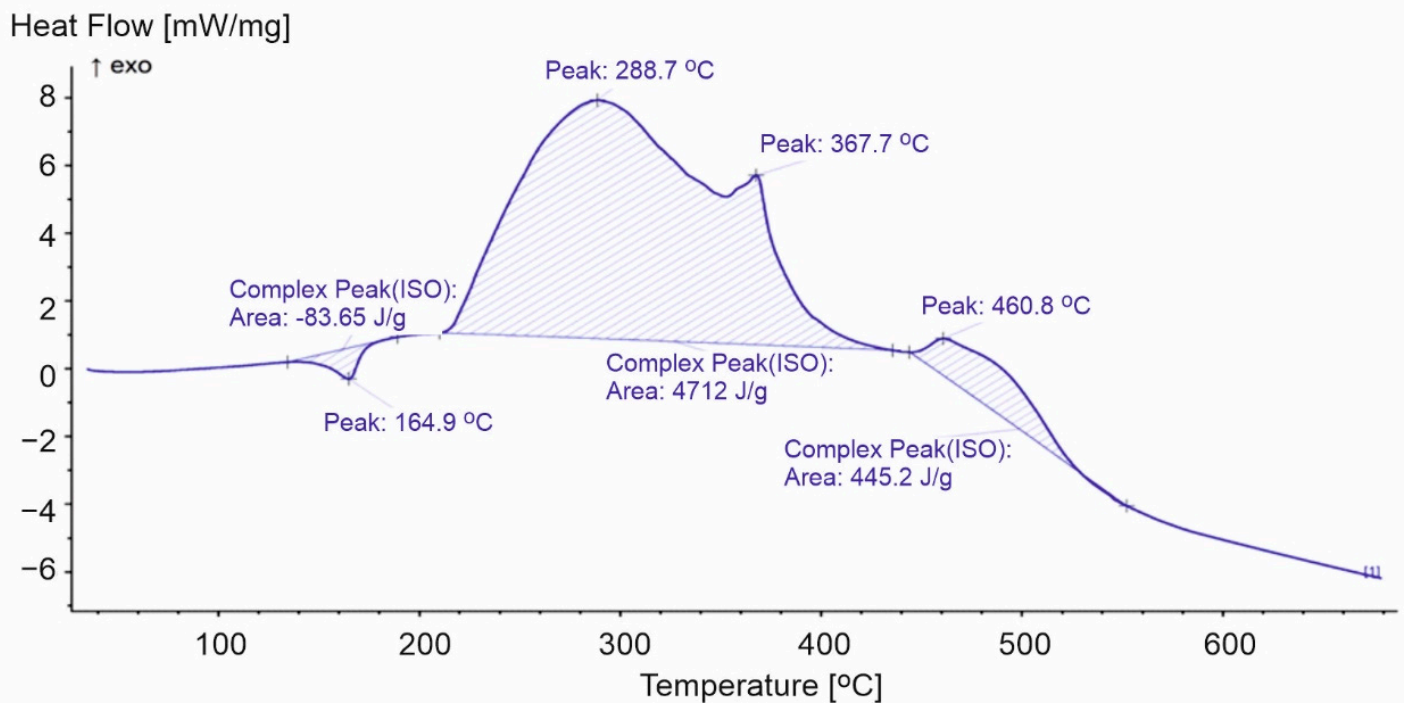

Figure 5. DSC curve for PP-1.

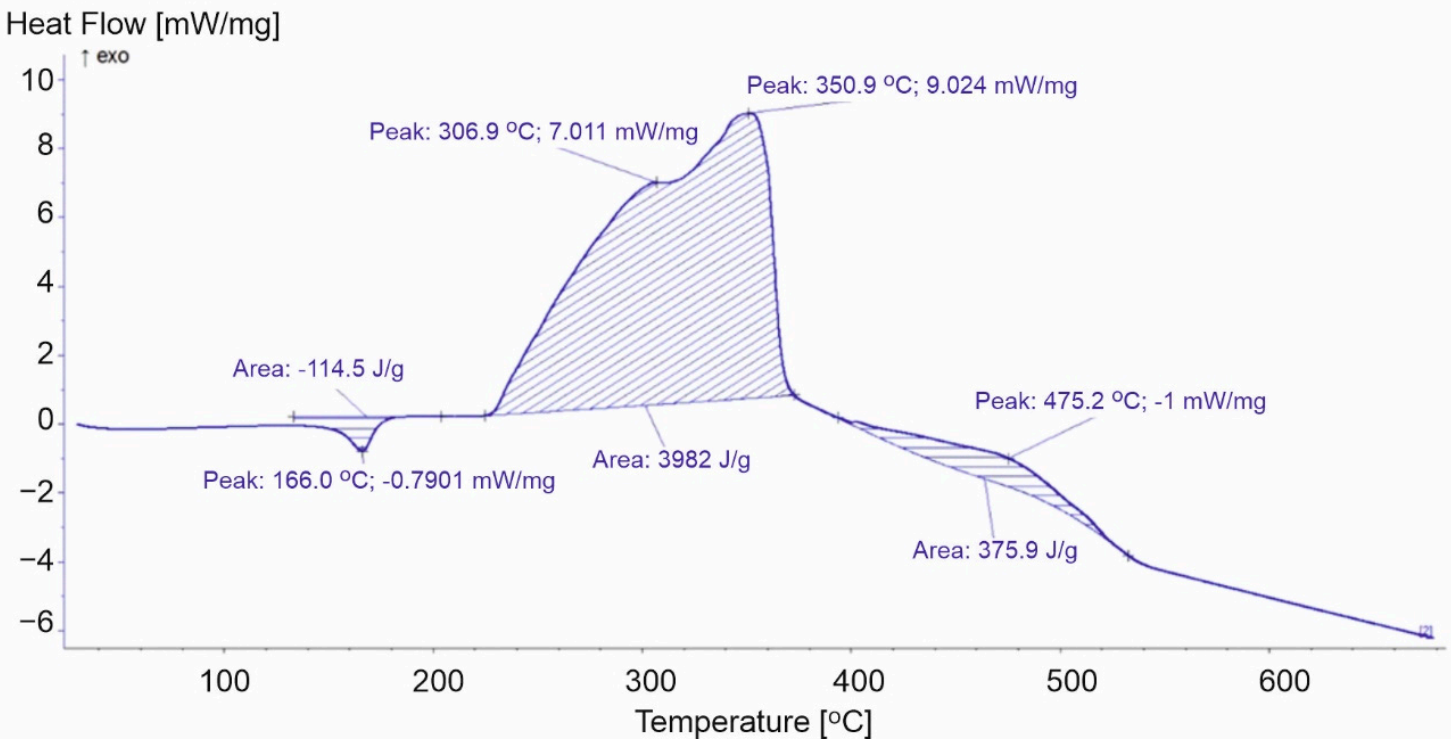

Figure 6. DSC curve for PP-2.

Table 2. Selected parameters for the DSC analysis for polypropylene.

\begin{tabular}{cccc}
\hline Parameters of Calorimetric Analysis & PP-1 & PP-2 & PP-3 \\
\hline 1st peak $\left[{ }^{\circ} \mathrm{C}\right]$ & 164.9 & 166.0 & 163.8 \\
2nd peak $\left[{ }^{\circ} \mathrm{C}\right]$ & 288.7 & 306.9 & 295.1 \\
3rd peak $\left[{ }^{\circ} \mathrm{C}\right]$ & 367.7 & 350.9 & 355.3 \\
Energy of the 1st transformation $[\mathrm{J} / \mathrm{g}]$ & 83.65 & 114.5 & 27.56 \\
Energy of the 2nd transformation $[\mathrm{J} / \mathrm{g}]$ & 4712 & 3982 & 3951 \\
Energy of the 3rd transformation $[\mathrm{J} / \mathrm{g}]$ & 445.2 & 375.9 & 332.7 \\
\hline
\end{tabular}




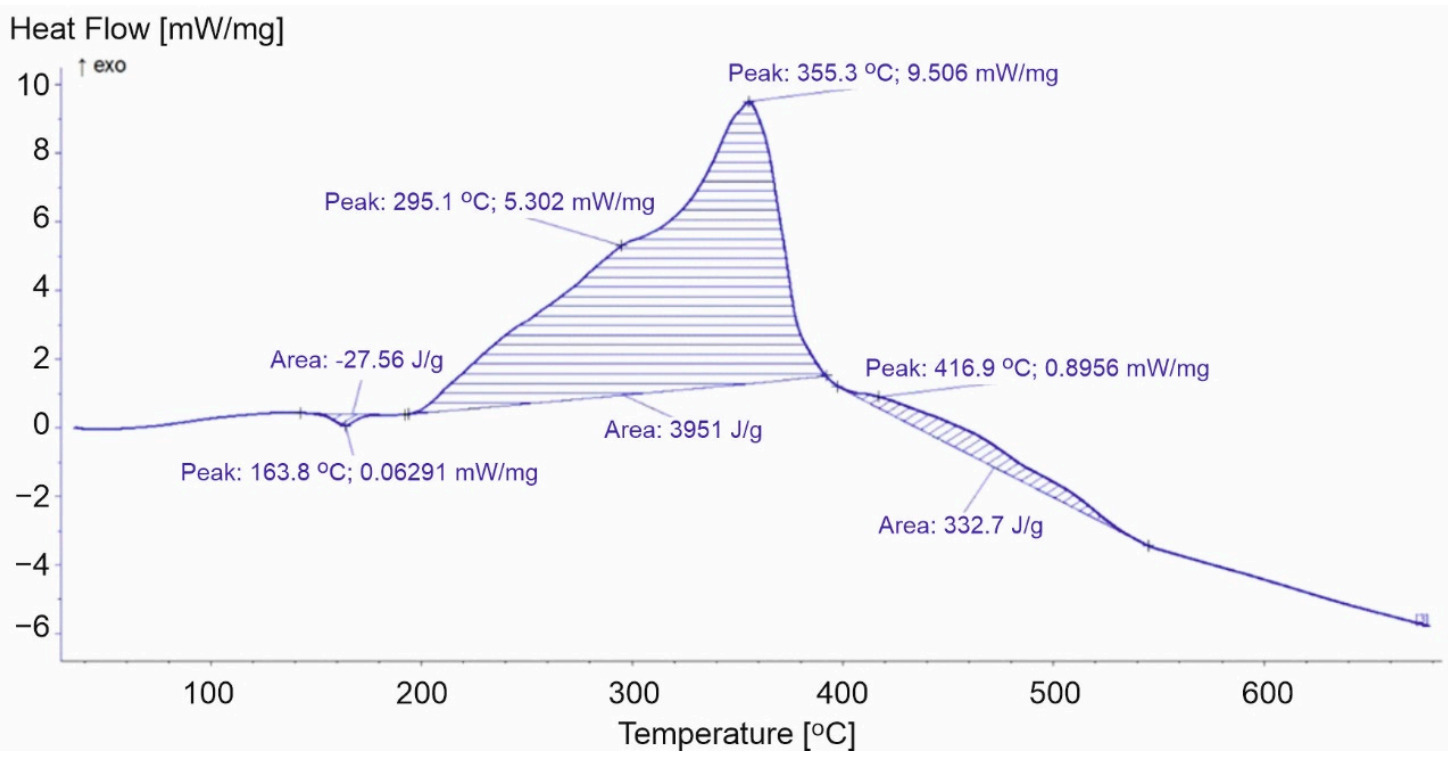

Figure 7. DSC curve for PP-3.

\subsection{TG DSC Analysis of Decomposition Process of Plastics Made of Polystyrene}

The analysis of the TG and DTG curves for PS-1 (Figure 8) indicated that thermal decomposition took place in two steps. The temperature range for the first step was equal to $280.2-433.3{ }^{\circ} \mathrm{C}$ (the remaining mass after the test was equal to $1.6 \%$ of the original sample mass) (Figure 8). In contrast, PS-0 was characterized by a one-step decomposition process and took place from $260{ }^{\circ} \mathrm{C}$ to $424^{\circ} \mathrm{C}$ with a maximum speed of $392{ }^{\circ} \mathrm{C}$ [37].

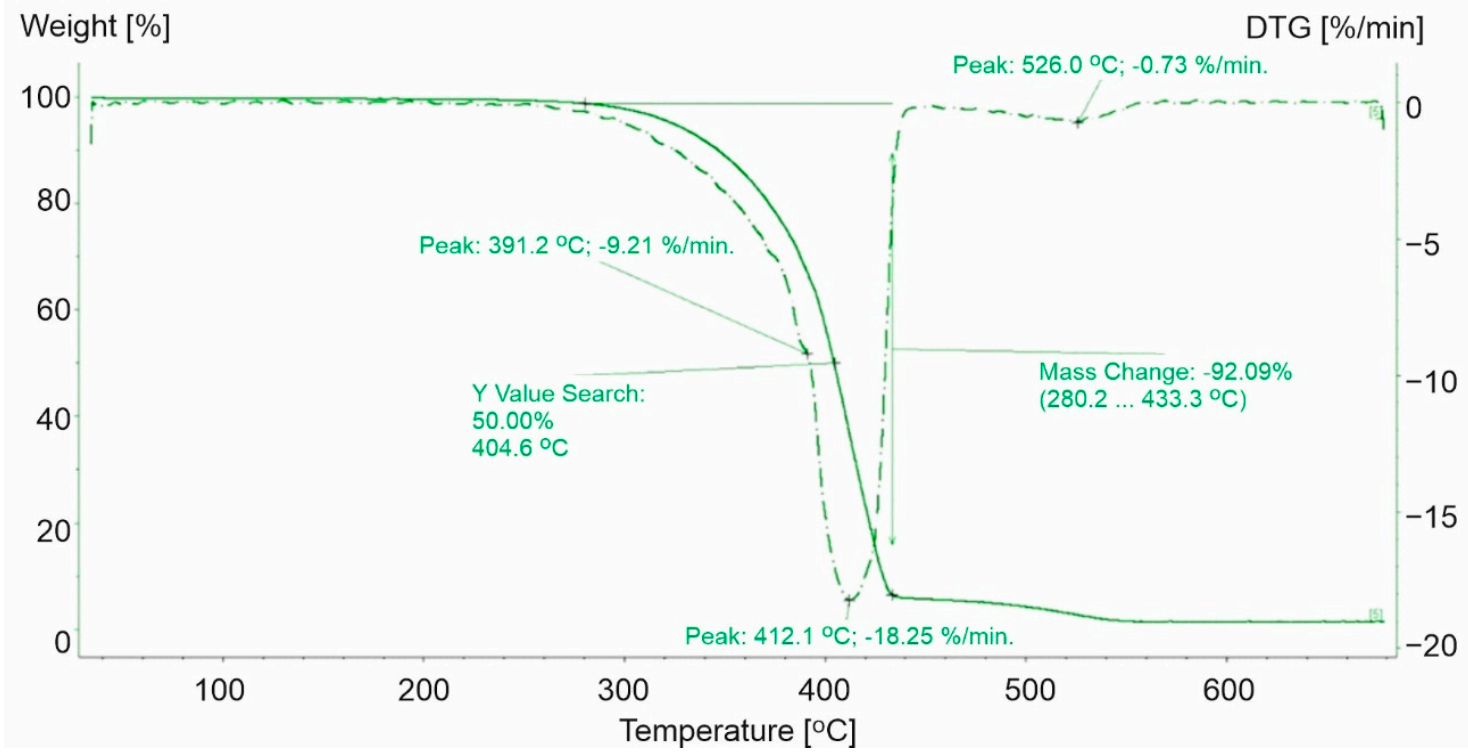

Figure 8. TG and DTG curves for PS-1. The green line presents TG curve, while the green dot line presents DTG curve.

For the second step of the decomposition process for PS-1, the mass loss rate reached $0.73{ }^{\circ} \mathrm{C} / \mathrm{min}$ at a temperature equal to $526{ }^{\circ} \mathrm{C}$ (above the temperature of the end of the decomposition process of pure polystyrene) (Figure 8 ). The differences during the thermal decomposition of PS-1 and PS-0 were caused by the presence of additives used in the processing of the materials. Their presence was characterized by the irregular course of the sample mass loss rate and the two-step process. It was observed that the application 
of other substances increased the initial temperature of the decomposition process and delayed the time necessary to reach the maximum decomposition rate (Table 3).

Table 3. Selected parameters for the thermal decomposition process for polystyrene.

\begin{tabular}{ccc}
\hline Parameters of Thermal Decomposition & PS-0 & PS-1 \\
\hline Initial decomposition temperature $\left[{ }^{\circ} \mathrm{C}\right]$ & 260.0 & 280.2 \\
End temperature of 1st stage of decomposition $\left[{ }^{\circ} \mathrm{C}\right]$ & 424.0 & 433.3 \\
Loss of weight for 1st stage of decomposition [\%] & 98.0 & 92.1 \\
Temperature of loss of 50\% of weight [ $\left.{ }^{\circ} \mathrm{C}\right]$ & - & 404.6 \\
Maximum rate of weight loss [\%/min] & - & 18.2 \\
Temperature of maximum rate of weight loss $\left[{ }^{\circ} \mathrm{C}\right]$ & 392.0 & 412.1 \\
Maximum rate of weight loss for 2 nd stage $[\% / \mathrm{min}]$ & - & 0.7 \\
Temperature of maximum rate of weight loss for $2 \mathrm{nd}$ stage $\left[{ }^{\circ} \mathrm{C}\right]$ & - & 526.0 \\
Residual mass [\%] & 2.0 & 1.4 \\
\hline
\end{tabular}

Moreover, the DSC curve indicated that during the loss of weight of the analyzed sample, exothermic and endothermic changes appeared. Sample decomposition was preceded by a low energy endothermic reaction at a maximum peak equal to $250{ }^{\circ} \mathrm{C}$. The conducted analysis indicated that over $92 \%$ of sample weight loss decomposed at the first stage, where the maximum speed of decomposition was observed at $412{ }^{\circ} \mathrm{C}$. Our observations align with Wong et al., who showed that at $420{ }^{\circ} \mathrm{C}$ polystyrene decomposed completely within $10 \mathrm{~min}$ [44]. The mechanism of thermal decomposition of polystyrene is complex and includes reaction initiation at the ends of polymers chains, depolymerization, oxidation, an intramolecular shift of the hydrogen atom, and kinetic chain termination by recombination or disproportionation (dismutation) [31]. These processes run both with absorption and the transfer of energy to the surroundings (Figure 9).

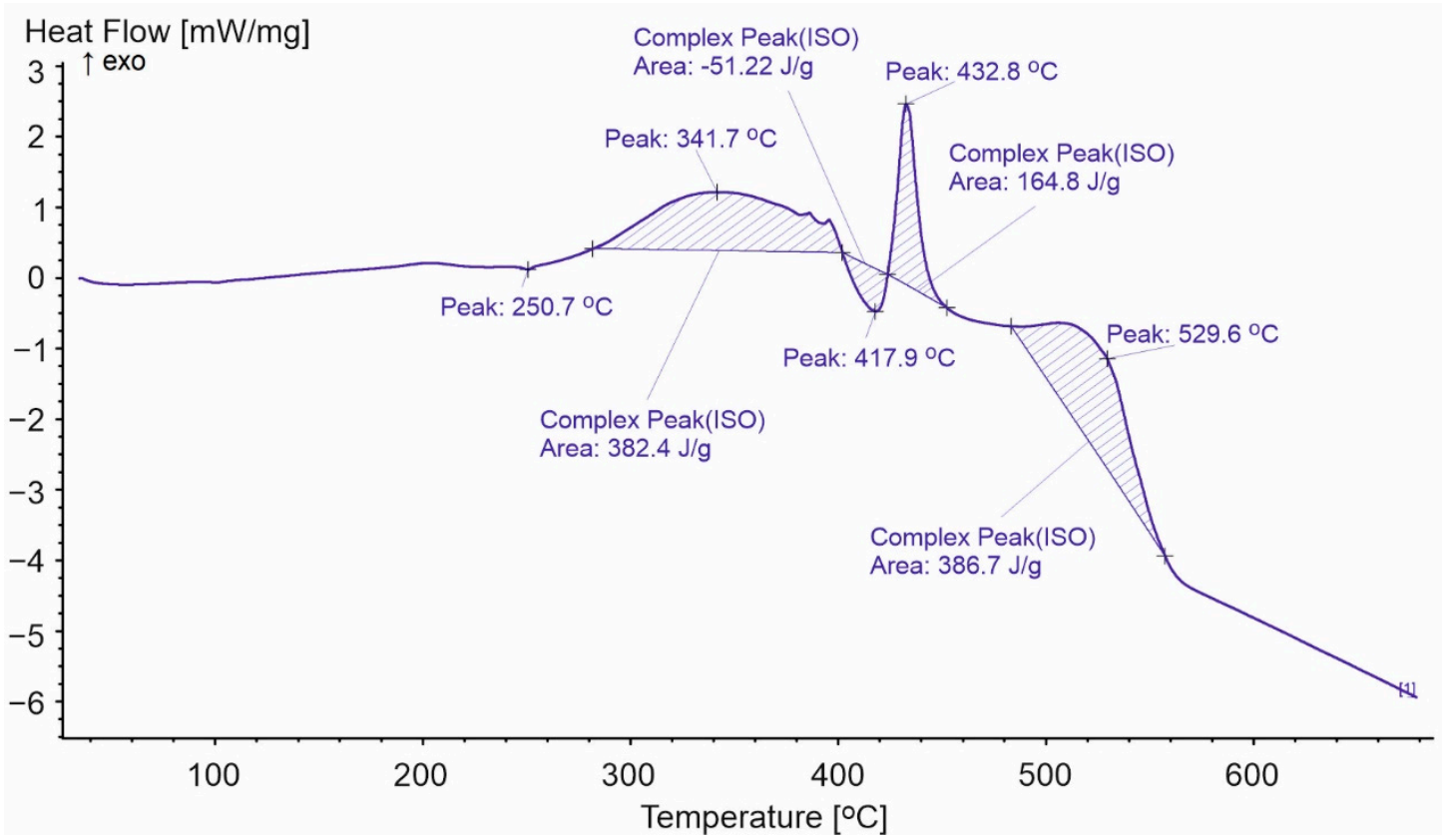

Figure 9. DSC curve for PS-1.

\subsection{TG DSC Analysis of Decomposition Process of Plastics Made of Polyethylene Terephthalate}

The initial temperature of the decomposition process of the tested sample was much lower $\left(329.8^{\circ} \mathrm{C}\right)$ compared to PET-0 $\left(390^{\circ} \mathrm{C}\right)$ (Figure 10). In the study of PET-1, the beginning of weight loss was correlated with the initial temperature of internal changes based on the DSC results. Moreover, in the study of PET-0, this value was determined based on the loss of a specific weight. A temperature of $573.7^{\circ} \mathrm{C}$ indicated the end of 
the decomposition process of the analyzed sample, which coincides with the result of PET-0 [15,28].

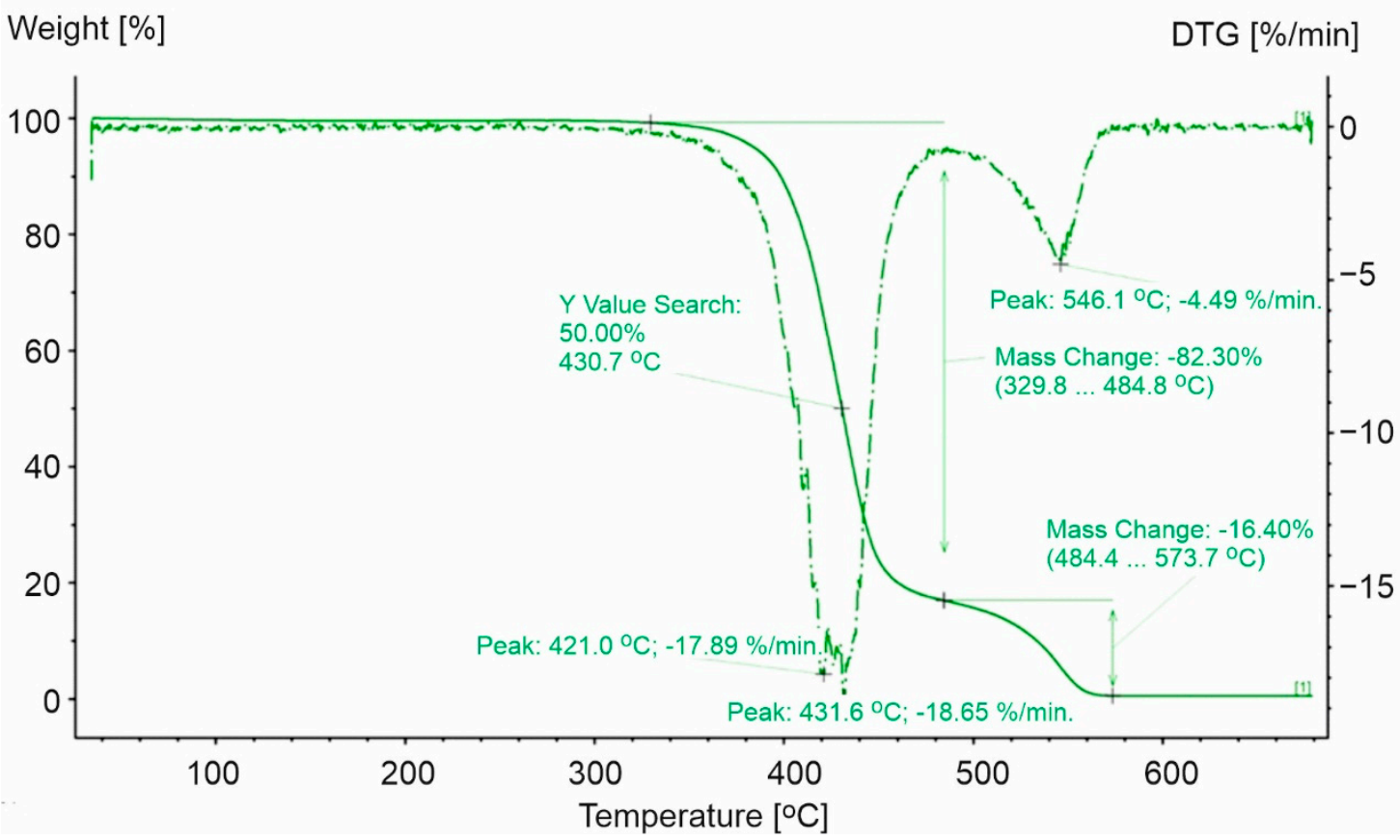

Figure 10. TG and DTG curves for PET-1. The green line presents TG curve, while the green dot line presents DTG curve.

The process of thermal decomposition of PET-1 and PET-0 took place in two steps. The weight loss in the first step was equal to $82.33 \%$ for PET- 1 and in the second step to $16.4 \%$ of its weight (Figure 10), while the loss for PET-0 was equal to $78.5 \%$ and $21.1 \%$, respectively (Table 4). The differences proved that the influence of the additives present in the material affected the course of the decomposition process.

Table 4. Selected parameters for the thermal decomposition process for PET-0 and PET-1.

\begin{tabular}{ccc}
\hline Parameters of Thermal Decomposition & PET-0 & PET-1 \\
\hline Initial decomposition temperature $\left[{ }^{\circ} \mathrm{C}\right]$ & 390.0 & 329.8 \\
End temperature of 1st stage of decomposition $\left[{ }^{\circ} \mathrm{C}\right]$ & - & 484.8 \\
Loss of weight for 1st stage of decomposition $[\%]$ & 78.5 & 82.3 \\
Temperature of loss of 50\% of weight $\left[{ }^{\circ} \mathrm{C}\right]$ & & 430.7 \\
End temperature of 2nd stage of decomposition $\left[{ }^{\circ} \mathrm{C}\right]$ & 575.0 & 573.7 \\
Loss of weight for 2nd stage of decomposition $[\%]$ & 21.1 & 16.4 \\
Maximum rate of weight loss [\%/min] & - & 18.65 \\
Temperature of maximum rate of weight loss $\left[{ }^{\circ} \mathrm{C}\right]$ & - & 431.6 \\
Maximum rate of weight loss for 2nd stage $[\% / \mathrm{min}]$ & - & 4.49 \\
Temperature of maximum rate of weight loss for $2 \mathrm{nd} \mathrm{stage}\left[{ }^{\circ} \mathrm{C}\right]$ & - & 546.1 \\
Residual mass [\%] & 0.4 & 1.3 \\
\hline
\end{tabular}

The comparison of the TG and DTG curves in Figure 10 with the calorimetric curves shown in Figure 11 indicated that the endothermic transformation observed at $249.4^{\circ} \mathrm{C}$ was not related to weight change. However, an internal transformation took place with the absorption of energy from the environment. Endothermic transformation initiates thermal decomposition combined with weight change, which turns into an exothermic transformation. The exothermic peaks at $422.3^{\circ} \mathrm{C}$ and $546.5^{\circ} \mathrm{C}$ correlated with the temperature of the maximum rate of weight loss (Figure 10). 


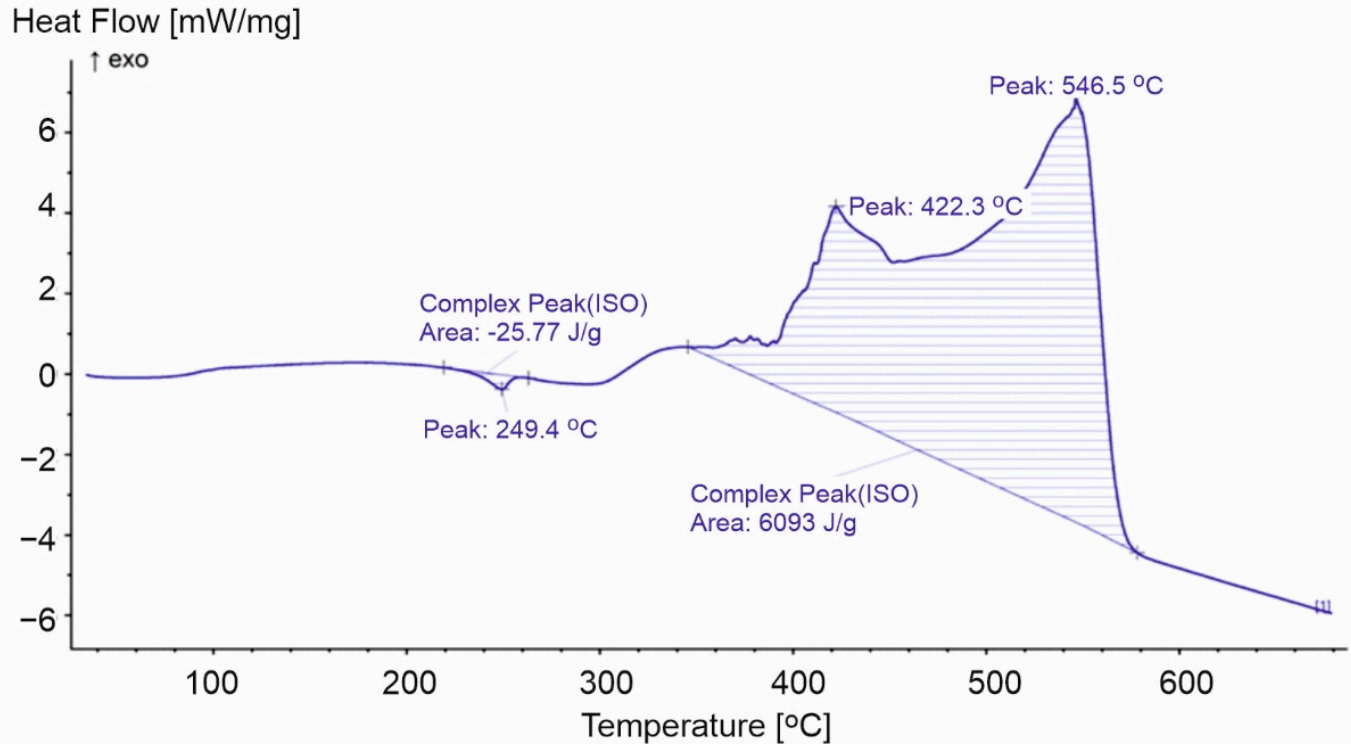

Figure 11. DSC curve for PET-1.

\section{Discussion}

It was observed that the thermal decomposition of the analyzed materials began at different temperatures (Figure 12). The lowest temperature $\left(194{ }^{\circ} \mathrm{C}\right)$ was observed for the PP-3 sample, while the highest was for PET-1 $\left(329.8^{\circ} \mathrm{C}\right)$. Furthermore, thermal destruction of PS- 1 began at $280{ }^{\circ} \mathrm{C}$.

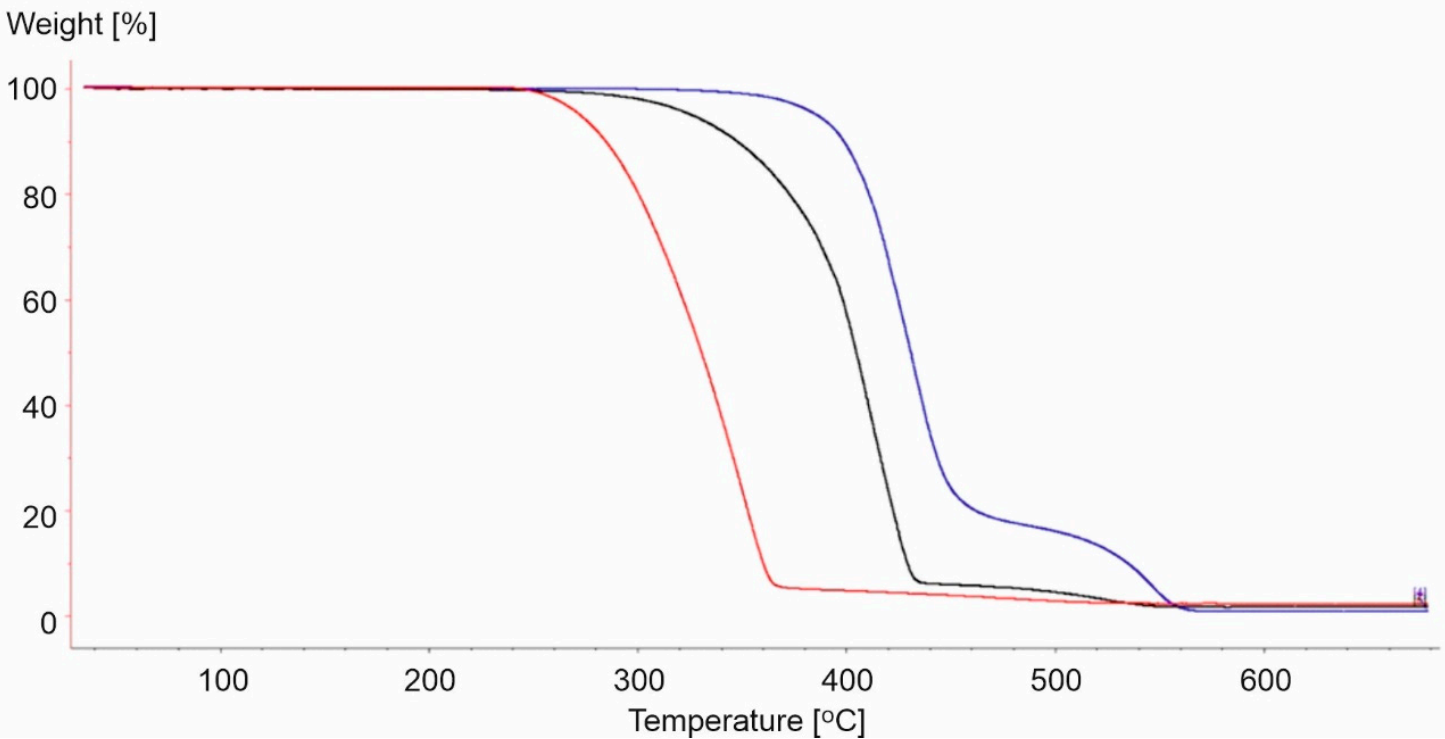

Figure 12. TG curves for PP-3 (red line), PS-1 (black line), and PET-1 (blue line).

Therefore, the loss of half the weight for PP-3 was observed at a lower temperature $\left(340{ }^{\circ} \mathrm{C}\right.$ ) compared to $405^{\circ} \mathrm{C}$ and $431^{\circ} \mathrm{C}$ for PS-1 and PET-1, respectively. Furthermore, PET-1 presented the most distinct course of the second stage of decomposition, which ended at $574{ }^{\circ} \mathrm{C}$.

In order to refer to the obtained experimental results, a review was carried out of the values of bond dissociation energies available in the literature to propose a dissociation mechanism of particular polymer molecules with respect to structural similarities of the selected organic compounds described in [45]. 
The initial step in the formation of oxygen bonds is a reaction in which a radical on the carbon chain is created [46]. For both PP and PS, the formation of a radical, by reaction with oxygen or pyrolysis, will be more favored on the $3^{\circ}$ carbon atom than on the $2^{\circ}$ carbon atom [47]. The reaction with $\mathrm{O}_{2}$ will lead to the formation of a tertiary hydroperoxide (Figure 13). The formation of the radical on PS will be easier than on PP due to the lower dissociation energy (BDE-bond dissociation energy) of the C-H bond in position $\beta$ in relation to the aromatic ring. This can be illustrated by the example of compounds with a similar environment, 2-Phenylpropane and 2-Methylpropane for PS and PP, respectively. BDEs for 2-Phenylpropane is $\mathrm{DH}_{0}(\mathrm{C}-\mathrm{H})=348 \mathrm{~kJ} / \mathrm{mol}$, while for 2Methylpropane $\mathrm{DH}_{0}(\mathrm{C}-\mathrm{H})=400.4 \mathrm{~kJ} / \mathrm{mol}$ [45]. Furthermore, the hydrogen bond breaking to form a radical on the $2^{\circ}$ carbon atom costs ca. $10 \mathrm{~kJ} / \mathrm{mol}$ more (e.g., for n-Propane, the $\mathrm{C}-\mathrm{H}$ bond breaking on the central carbon atom $\left.\mathrm{DH}_{0}(\mathrm{C}-\mathrm{H})=410.5 \mathrm{~kJ} / \mathrm{mol}\right)$ [45].

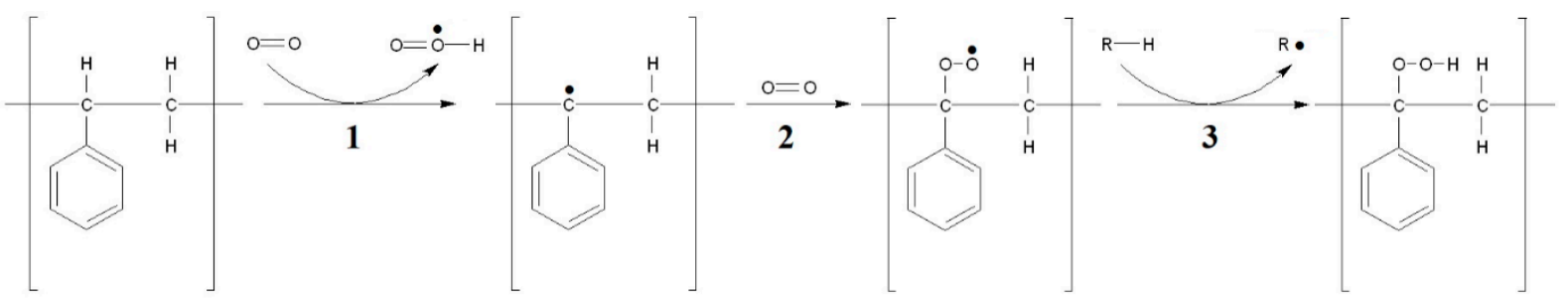

Figure 13. The possible scheme of formulation of tertiary peroxide by oxygen reaction using PS chain. The following symbols were applied: 1-an attack of an oxygen molecule on a PS molecule with formation of a radical; 2-an attack of an oxygen molecule on a radical located on a tertiary carbon atom; 3 - transfer of hydrogen from cleavage of the $\mathrm{C}-\mathrm{H}$ bond of the polymer structure with formation of a hydroperoxide.

The presence of hindered phenols $(\mathrm{PhOH})$ with strong reducing properties can significantly slow down the polymer degradation process in the initial stage [47-49]. It is presumed that this could be due to the transfer of the hydrogen atom to the phenoxyl group, which causes stabilization of the peroxyl radical by the formation of hydroperoxide. In Figure 13, intramolecular hydrogen transfer in the PS structure is presented in reaction 3. In contrast to PP, polystyrene could form some phenolic compounds during the degradation process. However, it is rather unlikely, especially at the initial stage of the reaction. Breaking the $\mathrm{C}-\mathrm{H}$ bond in the aromatic ring is an energy expenditure of around $472.2 \mathrm{~kJ} / \mathrm{mol}$, and hence, it is much more than breaking the bond in the aliphatic chain [45]. Therefore, in the analyses of PS decomposition products, no phenolic compounds are observed, and practically, the dominant oxygen compound containing an aromatic ring is benzaldehyde $[11,50,51]$. Stabilizing hydrogen transfer directly from the structure of PS (Figure 13, reaction 3) will be, on the other hand, possible by breaking the $\mathrm{C}-\mathrm{H}$ bond from other sides of the polymer molecule, with the easiest breaking point in position $\beta$ relative to the aromatic ring. Due to the previously mentioned bond dissociation energy, this is likely to be easier in PS than PP. The facilitated transfer and formation of hydroperoxide may be the reason for the much higher onset temperature of PS decomposition. The formation of hydroperoxide inhibits the decomposition of the carbon chain in position $\beta$ ( $\beta$ scission) if hydrogen transfer is possible to form the alcohol, as shown in Figure 14. Moreover, this transfer, as mentioned earlier, is easier in the PS molecule. 


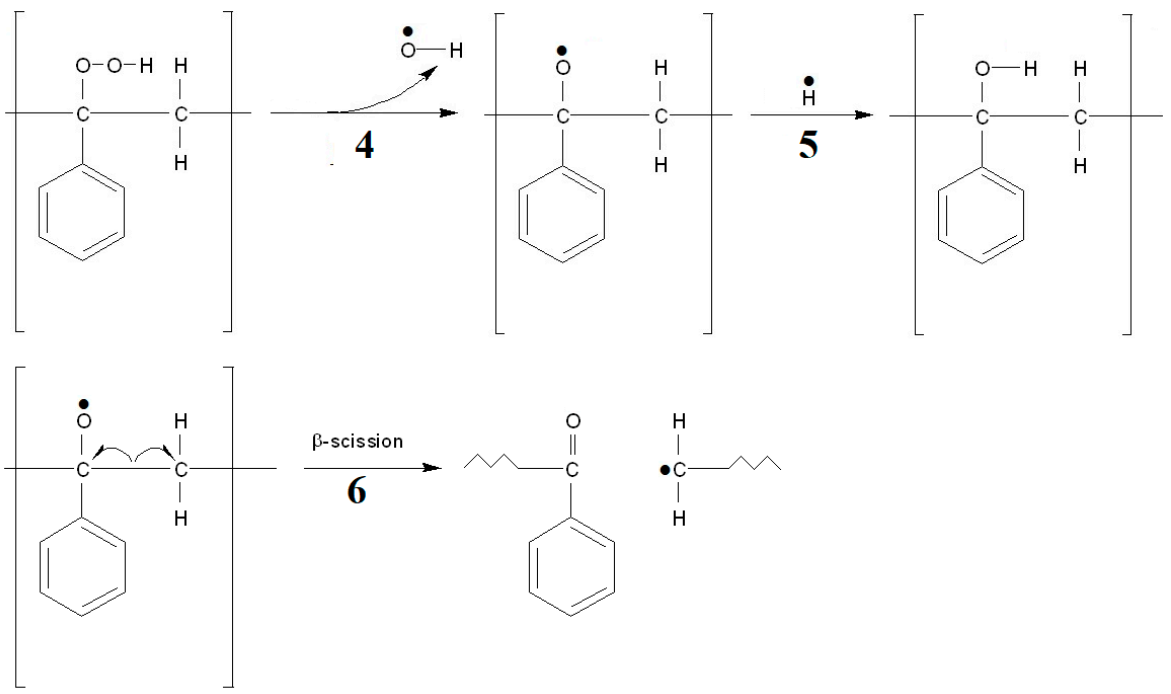

Figure 14. The proposed degradation pathways of tertiary hydroperoxide. The following symbols were applied: 4-decomposition of the hydroperoxide on the $\mathrm{O}-\mathrm{O}$ bond with departure of the $\mathrm{OH}$ radical; 5-reaction of the resulting tertiary oxide radical with formation of alcohol; 6-decomposition at the position of the tertiary oxide radical.

The thermal effect observed in this study for PS is less intense than that for PP. The decomposition of delocalized bonds between carbon atoms of the aromatic ring requires a very high energy input $\left(\mathrm{DH}_{0}(\mathrm{C}-\mathrm{C})=518 \mathrm{~kJ} / \mathrm{mol}\right)$, which may explain the presence of an endothermic peak with its maximum at $417{ }^{\circ} \mathrm{C}$. Hence, it is much easier for the C-C bond to break down in position $\beta$ in relation to the ring. This causes the separation of a styrene molecule, which leaves the combustion zone non-oxidized, contrary to the small and easily volatile vapors of the resulting propene. Therefore, the DSC curves indicate that the amount of heat recorded for exothermic processes of PP is more than $4000 \mathrm{~J} / \mathrm{g}$ and for PS less than $1000 \mathrm{~J} / \mathrm{g}$. This observation is confirmed by the studies conducted by Zhu et al., who has identified styrene as the predominant product under both oxidative and pyrolysis conditions in the presence of nitrogen [51]. Peterson et al. indicated that $40 \%$ of the products are styrene during thermal PS decomposition [18]. The decomposition of the C-C bond with the formation of styrene requires relatively little energy. For 2-Phenylpropane with a local bond system analogous to PS, the dissociation energy of the C-C bond in position $\beta$ relative to the ring is only $\mathrm{DH}_{0}(\mathrm{C}-\mathrm{C})=318 \mathrm{~kJ} / \mathrm{mol}$ [45]. Hence, dissociation at this position is relatively easy, which is also confirmed by computer simulations performed for the tristrene molecule [52].

When comparing PP, PS, and PET, it is worth noting that the process of mass loss starts last in the case of PET. To explain the reason for later degradation, it is worth paying attention to the characteristics of the energy of bonds in PET by comparing it to the energy of breaking bonds in methyl benzoate: breaking the $-\mathrm{C}-\mathrm{H}$ bond in the PET ethylene chain is more difficult. The energy of the $\mathrm{C}-\mathrm{H}$ bond in the $-\mathrm{CH}_{3}$ group of methyl benzoate is $418.4 \mathrm{~kJ} / \mathrm{mol}$, which is higher than in 2-Phenylpropane $\left(\mathrm{DH}_{0}(\mathrm{C}-\mathrm{H})=348 \mathrm{~kJ} / \mathrm{mol}\right)$ and 2Methylpropane $\left(\mathrm{DH}_{0}(\mathrm{C}-\mathrm{H})=400.4 \mathrm{~kJ} / \mathrm{mol}\right)$. It will, therefore, be more difficult to produce a radical by breaking the $\mathrm{C}-\mathrm{H}$ bond. Further, even more energy is required to break the C-C bond between the carboxyl group and the aromatic ring, where $436.8 \mathrm{~kJ} / \mathrm{mol}$ is required. The $\mathrm{C}-\mathrm{O}$ bond between a methyl group and a carboxyl group breaks more easily and needs $372.8 \mathrm{~kJ} / \mathrm{mol}$. It is more difficult to break a single $\mathrm{C}-\mathrm{O}$ bond in a carboxyl group that requires $413.4 \mathrm{~kJ} / \mathrm{mol}$. To determine the weakest point of the molecule, it is worth using the value of energy between carbon atoms of the ethylene group. For ethylene glycol, the value of $\mathrm{DH}_{0}(\mathrm{C}-\mathrm{C})$ is $358.2 \mathrm{~kJ} / \mathrm{mol}$, which is clearly less than in the other analyzed structural elements. However, these values are much higher than those required, such as breaking the $\mathrm{C}-\mathrm{C}$ bond in polystyrene $\left(\mathrm{DH}_{0}(\mathrm{C}-\mathrm{C})=318 \mathrm{~kJ} / \mathrm{mol}\right)$. Hence, the PET structure will break 
at a higher temperature than PS and PP. When the C-O bond between the carboxyl and ethylene groups is broken, a radical is formed on the oxygen atom of the carboxyl group, which decomposes very easily with the release of $\mathrm{CO}_{2}$ and the formation of a radical on the aromatic ring (Figure 15). The C-H bond energy in the phenyl radical $(327.6 \mathrm{~kJ} / \mathrm{mol})$ is much lower than in benzene $(472.2 \mathrm{~kJ} / \mathrm{mol})$ [45]. The degradation of the phenyl radical at a high temperature will require much less energy for its transformation than the breakdown of aromatic rings in PS. Therefore, the amount of energy obtained will also be much higher, which is confirmed by PET pyrolysis studies [53]. This is also confirmed by the DSC curves we obtained for PET, where the value of $6093 \mathrm{~J} / \mathrm{g}$ was obtained, which is even higher than for PP. Thus, there is a high probability that the PET degradation process occurs with more intensive fragmentation than in PS and PP. The course of the process, according to Figure 15, is confirmed by Brems et al. [53].
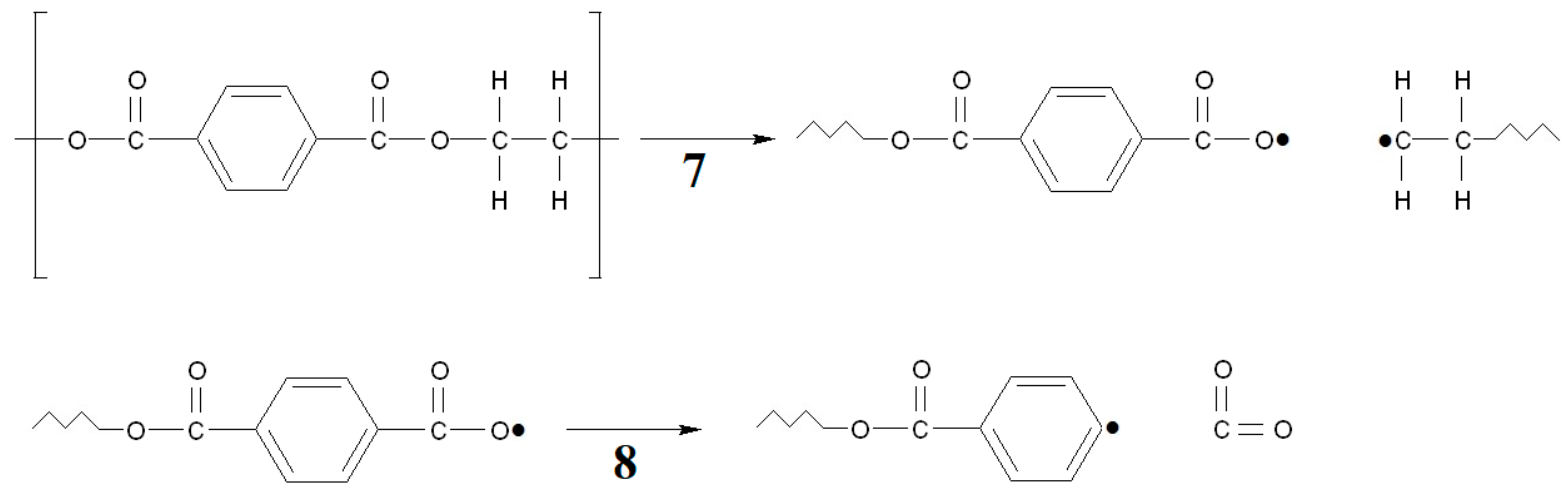

Figure 15. Exemplary degeneration of PET. The following symbols were applied: 7-Homolytic breaking of the C-O bond in PET between the carboxyl and ethylene groups; $8-\mathrm{CO}_{2}$; detachment with formation of phenyl radical.

Regarding breaking the $\mathrm{C}-\mathrm{C}$ bond in the ethylene element, the radical formed on the carbon atom is unstable and can be transformed with the formation of a formaldehyde molecule and a benzoyl radical (Figure 16, reaction 9, 10). For example, only $47 \mathrm{~kJ} / \mathrm{mol}$ [45] is needed to break the $\mathrm{C}-\mathrm{O}$ bond in the carboxyl group of the acetic acid radical $\left({ }^{*} \mathrm{CH}_{2} \mathrm{COOH}\right)$. The decomposition of the benzoyl radical also requires a small amount of energy, only $103.3 \mathrm{~kJ} / \mathrm{mol}$ [45]. This pathway would also result in the formation of a phenyl radical (Figure 16, reaction 11).

Interestingly, a similar sequence of oxidative transformations of PET is observed during photo-oxidation processes following Norrish Type I reaction mechanisms [54].

Brems et al. also observed the formation of terephthalic acid and vinyl compounds during PET pyrolysis [53], which corresponds to the Norrish Type II reaction with internal hydrogen transfer (Figure 17). In the case of PET, terephthalic acid and benzoic acid may constitute a significant part of post-pyrolytic residues.

The PP samples analyzed in our study were characterized by visible differences in thermal properties, which indicated differences in the structure. The most commonly used industrial propylene polymers, apart from the homopolymer, which is composed only of propylene units, are propylene and ethylene copolymers characterized by higher mechanical resistance [55-57]. The number of tertiary carbon atoms on the homopolymer will be much higher than the copolymer containing ethylene units. Only secondary carbon atoms will be present on the ethylene elements. Therefore, considering that the decay on the tertiary atom is easier than on the secondary atom, which is a result of the lower bond energy, we observed faster degradation of PP homopolymers (propylene homopolymer). This can be observed following the decomposition rate of the samples used in our study. The $50 \%$ weight loss temperature was the highest for PP- 0 that was a pure homopolymer $\left(\mathrm{T}=293{ }^{\circ} \mathrm{C}\right.$ ), while for PP-1, PP-2, and PP-3, the temperatures were equal to $322^{\circ} \mathrm{C}, 330.7^{\circ} \mathrm{C}$, and $339.6^{\circ} \mathrm{C}$, respectively. A similar dependence was observed for the temperature of 
the maximum rate of weight loss. Moreover, the maximum rate of weight loss was also observed for the PP-0 sample (Table 1). Hence, we speculate that the PP-1, PP-2, and PP-3 samples were copolymers in which, apart from the PP, the PE part was present. A similar observation was made for PS-0 and PS. However, the situation was different in the case of PET-0 and PET-1. A comparison of the decomposition onset temperature and the degree of weight loss in the first decomposition step indicated that PET-1 decomposed more easily. As indicated above, the weakest point of the PET molecule was the C-C bond between the carbon atoms of the ethylene group. The incorporation of units composed of more methylene units $\left(-\mathrm{CH}_{2}-\right)$ in a part of the copolymer molecule, instead of the ethylene group, increases the share of the weakest aliphatic $\mathrm{C}-\mathrm{C}$ bonds in the polymer molecule and facilitates its decomposition [53].

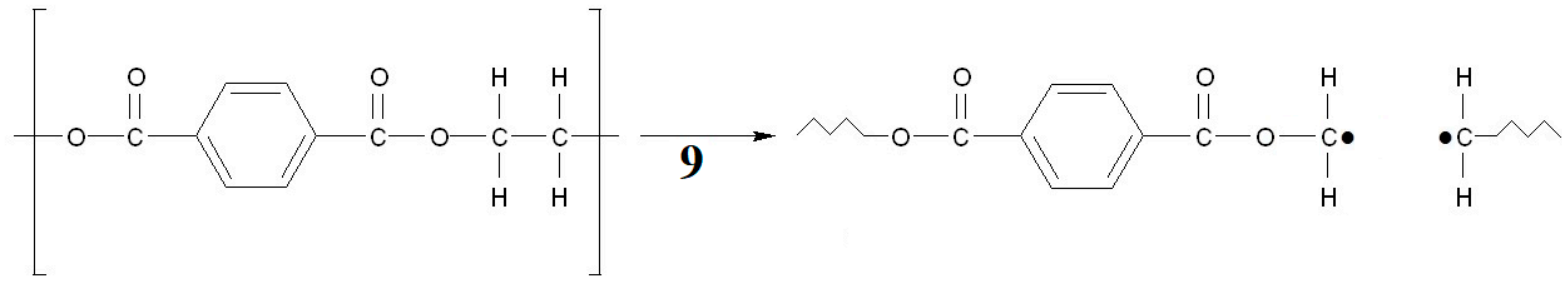<smiles>C#CC(OC(=O)c1ccc(C(=O)OCCCCC)cc1)[C@@H](C)CCCCOC(=O)c1ccc(C=O)cc1</smiles><smiles>C=CC1CC1C(=O)c1ccc(C(=O)OCCCCC)cc1</smiles>

Figure 16. Schematic degeneration of PET by bond breaking at the ethylene element. The following symbols were applied: 9 -cleavage of the $\mathrm{C}-\mathrm{C}$ bond in the ethylene group; 10 -formation of a benzoyl radical with a formaldehyde moiety; 11—cleavage of the benzoyl radical with formation of a phenyl radical.

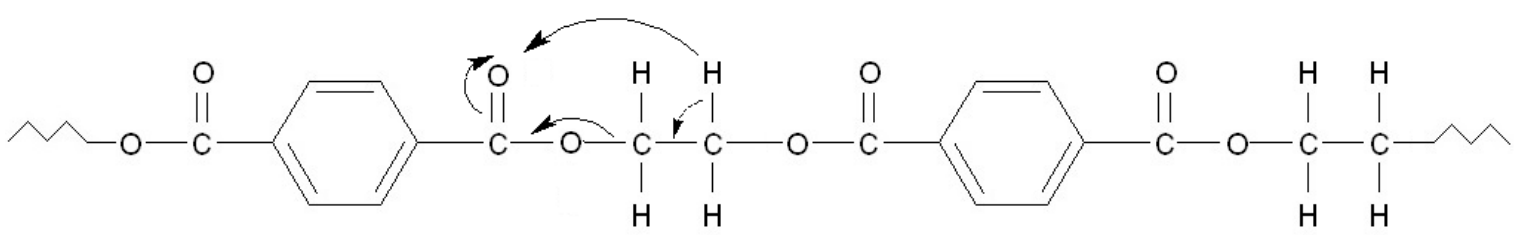<smiles>[Y][V]C</smiles><smiles>CCCCOC(=O)c1ccc(C(=O)O)cc1</smiles><smiles>C=COC(=O)c1ccc(C(=O)OCCCCCC)cc1</smiles>

Figure 17. Schematic PET decomposition according to Norrish type reaction II. As a result, during subsequent reactions, terephthalic acid and derivatives containing vinyl group are formed. 


\section{Conclusions}

Plastic packaging still makes up a significant proportion of the waste collected in municipal landfills and poses a major risk in the event of fires. The thermal stability of these materials depends primarily on the type of polymer, the additives used, and the structure. Of the plastics subjected to testing, the PP plastics were found to have the lowest thermal stability, while the PET thermoplastics had the highest. The rate of degradation of PP and PS may be due to the relative weakness of C-H bonds on the tertiary carbon atom. The decomposition of this bond enables the stabilization of hydroperoxide, which with a sufficiently easy detachment of the hydrogen atom and intramolecular transfer, transforms into stable tertiary alcohol. Due to the ease of detachment of the hydrogen atom from the benzylic carbon atom, this process has a preferred progression for PS. Hence, PS degradation will occur at higher temperatures than PP. The low intramolecular transfer of hydrogen causes an increased amount of $\beta$-scission, causing fragmentation of the molecule.

Additionally, it was found that the smallest amount of heat during a fire would be decidedly generated by thermo-oxidation of PS-based plastics. This is due to the formation of a styrene molecule during heating, which is due to the high stability of bonds in the aromatic ring and volatility escaping from the combustion zone without oxidation. The PET, despite having an aromatic ring in its structure, also releases a very large amount of heat during the thermo-oxidation process. The amount is even higher than in the case of PP. Analyzing the potential mechanism suggests that during decomposition, a phenyl radical is produced, and its decomposition is much easier than that of the neutral aromatic ring. Therefore, fragmentation of PET molecules occurs more intensively than in the case of PS.

The PP-based plastics were found to have a lower maximum rate of weight loss and a shift in the $50 \%$ weight loss temperature towards lower temperature values compared to the base polymer and polystyrene and PET-based plastics.

Additionally, results show that the PP-1, PP-2, and PP-3 samples can consist of PP and PE copolymers, which was supported by the decomposition rates of the samples analyzed in our study. The $50 \%$ weight loss temperature and the temperature of the maximum rate of weight loss were lowest for PP-0, while the rate of weight loss was highest for PP-0. This indicated a faster decomposition of pure PP due to a greater proportion of tertiary carbon atoms compared to the copolymer-containing ethylene units. A similar observation was made for PS-0 and PS.

The PS-based packaging was found to start decomposing at a higher temperature than pure polystyrene. Unfortunately, the opposite trend was recorded for PET packaging. In the case of PET, faster degradation was observed for PET-1, which may indicate the presence of longer aliphatic elements in the molecule containing more methylene units, which increased the probability of breaking the C-C bond compared to PET containing an ethylene fragment.

Author Contributions: Conceptualization, M.M.-Ł. and T.W.; methodology, M.M.-Ł.; software, M.M.Ł; validation, M.M.-Ł., A.P. and A.P.-P.; formal analysis, M.M.-Ł., A.A., A.P. and A.P.-P.; investigation, M.M.-Ł., T.W., K.R. and D.D.; resources, M.M.-Ł.; data curation, M.M.-Ł. and A.P.; writing-original draft preparation, M.M.-E., T.W., A.A., A.P. and A.P.-P.; writing—review and editing, M.M.-E., A.P. and A.P.-P.; visualization, M.M.-Ł. and T.W.; supervision, M.M.-Ł. and A.P.; project administration, M.M.-Ł.; funding acquisition, M.M.-Ł. All authors have read and agreed to the published version of the manuscript.

Funding: Supported by the Polish Ministry of Science and Higher Education.

Institutional Review Board Statement: Not applicable.

Informed Consent Statement: Not applicable.

Data Availability Statement: Data is available on request from the corresponding author.

Conflicts of Interest: The authors declare no conflict of interest. 


\section{References}

1. Zhao, X.; Zhan, L.; Xie, B.; Gao, B. Products derived from waste plastics (PC, HIPS, ABS, PP and PA6) via hydrothermal treatment: Characterization and potential applications. Chemosphere 2018, 207, 742-752. [CrossRef]

2. Shamsuyeva, M.; Endres, H.J. Plastics in the context of the circular economy and sustainable plastics recycling: Comprehensive review on research development, standardization and market. Compos. Part C 2021, 6, 100168. [CrossRef]

3. Chun, B.-H.; Li, X.; Im, E.J.; Lee, K.-H.; Kim, S.H. Comparison of Pyrolysis Kinetics between Rigid and Flexible Polyurethanes. J. Ind. Eng. Chem. 2007, 13, 1188-1193.

4. Olofinnade, O.; Chandra, S.; Chakraborty, P. Recycling of high impact polystyrene and low-density polyethylene plastic wastes in lightweight based concrete for sustainable construction. Mater. Proc. 2021, 38, 2151-2156. [CrossRef]

5. Hermabessiere, L.; Dehaut, A.; Paul-Pont, I.; Lacroix, C.; Jezequel, R.; Soudant, P.; Duflos, G. Occurrence and effects of plastic additives on marine environments and organisms: A review. Chemosphere 2017, 182, 781-793. [CrossRef] [PubMed]

6. Elanchezhiyan, S.S.; Prabhu, S.M.; Karthikeyan, P.; Park, C.P. Efficient and selective sequestration of perfluorinated compounds and hexavalent chromium ions using a multifunctional spinel matrix decorated carbon backbone N-rich polymer and their mechanistic investigations. J. Mol. Liq. 2021, 326, 115336. [CrossRef]

7. Sevastyanov, G.M. Adiabatic heating effect in elastic-plastic contraction/expansion of spherical cavity in isotropic incompressible material. Eur. J. Mechanics-A/Solids 2021, 87, 104223. [CrossRef]

8. Richeton, J.; Ahzi, S.; Vecchio, K.S.; Jiang, F.C.; Adharapurapu, R.R. Influence of temperature and strain rate on the mechanical behavior of three amorphous polymers: Characterization and modeling of the compressive yield stress. Int. J. Solids Struct. 2006, 43, 2318-2335. [CrossRef]

9. Ou, Y.; Sun, Y.; Guo, X.; Jiao, Q. Investigation on the thermal decomposition of hydroxyl terminated polyether based polyurethanes with inert and energetic plasticizers by DSC-TG-MS-FTIR. J. Anal. Appl. Pyrolysis 2018, 132, 94-101. [CrossRef]

10. Dzieciol, M.; Trzeszczynski, J. Studies of Temperature Influence on Volatile Thermal Degradation Products of Poly(ethylene terephthalate). J. Appl. Polym. Sci. 1998, 69, 2377-2381. [CrossRef]

11. Seleem, S.; Olivio, J.; Schiraldi, D.A. Comparison of Thermal Decomposition of Polystyrene Products vs. Bio-Based Polymer Aerogels. Therm. Decompos. Bio-Based Polym. Aerogels 2017, 117, 50-60. [CrossRef]

12. Yates, J.; Deeney, M.; White, H.; Joy, E.; Kalamatianou, S.; Kadiyala, S. Protocol: Plastics in the food system: Human health, economic and environmental impacts. A scoping review. Campbell Collab. 2019, 15, e1033. [CrossRef]

13. Steinmetz, Z.; Wollmann, C.; Schaefer, M.; Buchmann, C.; David, J.; Tröger, J.; Munoz, K.; Fror, O.; Schaumann, G.E. Plastic mulching in agriculture. Trading short-term agronomic benefits for long-term soil degradation. Sci. Total Environ. 2016, 550, 690-705. [CrossRef] [PubMed]

14. Alamri, M.S.; Qasem, A.A.A.; Mohamed, A.A.; Hussain, S.; Ibraheem, M.A.; Shamlan, G.; Alqah, H.A.; Qasha, A.S. Food packaging's materials: A food safety perspective. Saudi J. Biol. Sci. 2021, 28, 4490-4499. [CrossRef]

15. Wu, Z.Z.; Ni, Y.P.; Fu, T.; Liu, B.W.; Wu, W.S.; Chen, L.; Wang, X.L.; Wang, Y.Z. Effect of biphenyl biimide structure on the thermal stability, flame retardancy and pyrolysis behavior of PET. Polym. Degrad. Stab. 2018, 155, 162-172. [CrossRef]

16. Bertin, D.; Leblanc, M.; Marque, S.R.A.; Siri, D. Polypropylene degradation: Theoretical and experimental investigations. Polym. Degrad. Stab. 2010, 95, 782-791. [CrossRef]

17. Botelho, G.; Queiros, A.; Liberal, S.; Gijsman, P. Studies on thermal and thermo-oxidative degradation of poly(ethylene terephthalate) and poly(butylene terephthalate). Polym. Degrad. Stab. 2001, 74, 39-48. [CrossRef]

18. Peterson, J.D.; Vyazovkin, S.; Wight, C.A. Kinetics of the Thermal and Thermo-Oxidative Degradation of Polystyrene, Polyethylene and Poly(propylene). Macromol. Chem. Phys. 2001, 202, 775-784. [CrossRef]

19. Verma, R.; Vinoda, K.S.; Papireddy, M.; Gowda, A.N.S. Toxic Pollutants from Plastic Waste-A Review. Procedia Environ. Sci. 2016, 35, 701-708. [CrossRef]

20. Bwalya, A.; Lougheed, G.; Kashef, A.; Saber, H. Survey Results of Combustible Contents and Floor Areas in Canadian MultiFamily Dwellings. Fire Technol. 2011, 47, 1121-1140. [CrossRef]

21. Majder-Lopatka, M.; Wesierski, T.; Dmochowska, A.; Salamonowicz, Z.; Polanczyk, A. The Influence of Hydrogen on the Indications of the Electrochemical Carbon Monoxide Sensors. Sustainability 2020, 12, 14. [CrossRef]

22. Rogula-Kozłowska, W.; Bralewska, K.; Rogula-Kopiec, P.; Makowski, R.; Majder-Łopatka, M.; Łukawski, A.; Brandyk, A Respirable particles and polycyclic aromatic hydrocarbons at two Polish fire stations. Build. Environ. 2020, 184, 107255. [CrossRef]

23. Noroozi, M.; Panahi-Sarmad, M.; Abrisham, M.; Amirkiai, A.; Asghari, N.; Golbaten-Mofrad, H.; Karimpour-Motlagh, N.; Goodarzi, V.; Bahramian, A.R.; Zahiri, B. Nanostructure of Aerogels and their applications in thermal energy insulation. ASC Appl. Energy Mater. 2019, 2, 5319-5349. [CrossRef]

24. Majder-Lopatka, M.; Rogula-Kozlowska, W.; Wasik, W. The Application of Stand-Off Infrared Detection to Identify Air Pollutants. In Proceedings of the Application of Stand-Off Infrared Detection to Identify Air Pollutants, 2018, E3S Web of Conferences, Polanica Zdroj, Poland, 3 July 2018.

25. Kok, M.V. Temperature-controlled combustion and kinetics of different rank coal samples. J. Therm. Anal. Calorim. 2005, 79, 175-180. [CrossRef]

26. Schindler, A.; Doedt, M.; Gezgin, S.; Menzel, J.; Schmolzer, S. Identification of polymers by means of DSC, TG, STA and computer-assisted database search. J. Therm. Anal. Calorim. 2017, 129, 833-842. [CrossRef] 
27. Zhao, T.; Yang, S.; Hu, X.; Song, W.; Cai, J.; Xu, Q. Restraining effect of nitrogen on coal oxidation in different stages: Nonisothermal TG-DSC and EPR research. Int. J. Min. Sci. Technol. 2020, 30, 387-395. [CrossRef]

28. Badia, J.D.; Martinez-Felipe, A.; Santonja-Blasco, L.; Ribes-Greus, A. Thermal and thermo-oxidative stability of reprocessed poly(ethylene terephthalate). J. Anal. Appl. Pyrolysis 2013, 99, 191-202. [CrossRef]

29. Butler, C.H.; Whitmore, P.M. Measurement of peroxides in the volatile degradation products of polypropylene photooxidation. Polym. Degrad. Stab. 2013, 98, 471-473. [CrossRef]

30. Saikrasun, S.; Saengsuwan, S. Thermal decomposition kinetics of in situ reinforcing composite based on polypropylene and liquid crystalline polymer. J. Mater. Process. Technol. 2009, 209, 3490-3500. [CrossRef]

31. Faravelli, T.; Pinciroli, M.; Pisano, F.; Bozzano, G.; Dente, M.; Ranzi, E. Thermal degradation of polystyrene. J. Anal. Appl. Pyrolysis 2001, 60, 103-121. [CrossRef]

32. Dzieciol, M.; Trzeszczynski, J. Volatile products of poly(ethylene terephthalate) thermal degradation in nitrogen atmosphere. J. Appl. Polym. Sci. 2000, 77, 1894-1901. [CrossRef]

33. Yano, A.; Akai, N.; Ishii, H.; Satoh, C.; Hironiwa, T.; Millington, K.R.; Nakata, M. Thermal oxidative degradation of additive-free polypropylene pellets investigated by multichannel Fourier-transform chemiluminescence pectroscopy. Polym. Degrad. Stab. 2013, 98, 2680-2686. [CrossRef]

34. Forsstrom, D.; Hamskog, M.; Eriksson, P.; Terselius, B. Oxidation of unstabilised polypropylene particles as studied by microcalorimetry and chemiluminescence techniques. Polym. Degrad. Stab. 2003, 81, 81-88. [CrossRef]

35. Tahmasebi, A.; Yu, J.; Su, H.; Han, Y.; Lucas, J.; Zheng, H.; Wall, T. A differential scanning calorimetric (DSC) study on the characteristics and behavior of water in low-rank coals. Fuel 2014, 135, 243-252. [CrossRef]

36. Wong, A.C.Y.; Lam, F. Study of selected thermal characteristics of polypropylene/polyethylene binary blends using DSC and TGA. Polym. Test. 2002, 21, 691-696. [CrossRef]

37. Shapi, M.M. TG and DSC studies of some thermal properties and stability aspects of poly(acrylonitrile butadiene styrene), polystyrene and poly(acrylonitrile styrene) plastics. Thermochim. Acta 1991, 40, 273-276. [CrossRef]

38. Zhang, H.; Gao, E.; Zhang, X. Comprehensive study on the rule of spontaneous combustion coal in oxidation process by TG-DTA-FTIR technology. J. Power Technol. 2015, 95, 167-174.

39. Karimpour-Motlagh, N.; Ali Khonakdar, H.; Ali Jafari, S.M.; Mahjub, A.; Panahi-Sarmad, M.; Farahani Kasbi, S.; Shojaei, S.; Goodarzi, V.; Arjmand, M. Influence of polypropylene and nanoclay on thermal and thermo-oxidative degradation of poly(lactide acid): TG-FTIR, TG-DSC studies and kinetic analysis. Thermochim. Acta 2020, 691, 178709. [CrossRef]

40. Spicker, C.; Rudolph, N.; Kuhner, I.; Aumnate, C. The use of rheological behavior to monitor the processing and service life properties of recycled polypropylene. Food Packag. Shelf Life 2019, 19, 174-183. [CrossRef]

41. Brachet, P.; Hoydal, L.T.; Hinrichsen, E.L.; Melum, F. Modification of mechanical properties of recycled polypropylene from post-consumer containers. Waste Manag. 2008, 28, 2456-2464. [CrossRef] [PubMed]

42. Navarro Vidal, R.; López Martínez, J.; Parres, F.; Ferrándiz Bou, S. Process behavior of compatible polymer blends. Appl. Polym. Sci. 2012, 124, 2485-2493. [CrossRef]

43. Paik, P.; Kar, K. Kinetics of thermal degradation and estimation of lifetime for polypropylene particles: Effects of particle size Polym. Degrad. Stab. 2008, 93, 24-35. [CrossRef]

44. Wong, H.-W.; Broadbelt, L.J. Tertiary resource recovery from waste polymers via pyrolysis: Neat and binary mixture reactions of polypropylene and polystyrene. Ind. Eng. Chem. Res. 2001, 40, 4716-4723. [CrossRef]

45. Luo, Y.R. Comprehensive Handbook of Chemical Bond Energies; Taylor \& Francis: Milton, UK, 2007.

46. Troitskii, B.B.; Troitskaya, L.S.; Dmitriev, A.; Yakhnov, A.S. Inhibition of thermo-oxidative degradation of poly(methylmethacrylate) and polystyrene by C60. Eur. Polym. J. 2000, 36, 1073-1084. [CrossRef]

47. Gensler, R.; Plummer, C.J.G.; Kausch, H.H.; Kramer, E.; Pauquet, J.R.; Zweifel, H. Thermo-oxidative degradation of isotactic polypropylene at high temperatures: Phenolic antioxidants versus HAS. Polym. Degrad. Stab. 2000, 67, 195-208. [CrossRef]

48. Pospisil, J. Chemical and photochemical behaviour of phenolic antioxidants in polymer stabilization-A state of the art report, Part I. Polym. Degrad. Stab. 1993, 40, 217-232. [CrossRef]

49. Pospisil, J. Chemical and photochemical behaviour of phenolic antioxidants in polymer stabilization-A state of the art report, Part II. Polym. Degrad. Stab. 1993, 39, 103-115. [CrossRef]

50. Pacákova, V.; Leclercq, P.A.; Holotik, S.; Beroun, I. A Study of Oxidative Degradation of Plastics by GC and GC-MS. Anal. Lett. 1985, 18, 1759-1775. [CrossRef]

51. Zhu, X. Thermal and Thermo-Oxidative Degradation of Polystyrene with Ammonium Polyphosphate. J. Fire Sci. 1996, 14, 443-465.

52. Huang, J.; Meng, H.; Cheng, X.; Pan, G.; Cai, X.; Liu, J. Density functional theory study on bond dissociation energy of polystyrene trimer model compound. In IOP Conference Series: Materials Science and Engineering; IOP Publishing: Bristol, UK, 2020; pp. 1-8.

53. Brems, A.; Baeyens, J.; Vandecasteele, C.; Dewil, R. Polymeric Cracking of Waste Polyethylene Terephthalate to Chemicals and Energy. J. Air Waste Manag. Assoc. 2011, 61, 721-731. [CrossRef]

54. Sang, T.; Wallis, C.J.; Hill, G. Polyethylene terephthalate degradation under natural and accelerated weathering conditions. Eur. Polym. J. 2020, 136, 109873. [CrossRef]

55. Zhi-qiang, F.; Yu-qing, Z.; Jun-ting, X.; Hai-tao, W.; Lin-xian, F. Structure and properties of polypropylene/poly(ethylene-copropylene) in-situ blends synthesized by spherical Ziegler \pm Natta catalyst. Polymer 2001, 42, 5559-5566. 
56. Qi, D.; Xiaofeng, W.; Zhisheng, F.; Junting, X.; Zhiqiang, F. Regulation of morphology and mechanical properties of polypropylene/poly(ethylene-co-propylene) in-reactor alloys by multi-stage sequential polymerization. Polymer 2007, 48, 5905-5916.

57. Yandi, F.; Chunyu, Z.; Yanhu, X.; Wei, N.; Xuequan, Z.; Xiangling, J.; Shuqin, B. Effect of Copolymerization Time on the Microstructure and Properties of Polypropylene/Poly(ethylene-co-propylene) In-Reactor Alloys. Polym. J. 2009, 41, $1098-1104$. 